\title{
AdAPTIVE MultiResolution MOdulation FOR Multimedia TrafFic OVER NAKAGAMI FADING CHANNELS
}

\author{
Justin James, Annamalai Annamalai, Olusegun Odejide, and Dhadesugoor \\ Vaman \\ ARO Center for Battlefield Communications, Department of Electrical and Computer \\ Engineering, Prairie View A\&M University, Texas 77446 \\ [jjames3, aaannamalai, olodejide, and drvaman] @pvamu.edu
}

\begin{abstract}
Future wireless communications networks will be required to support a multitude of services with different reliability and latency requirements. However, achieving such flexible systems are challenging in Mobile Ad-hoc Networks (MANET) due to limited battery resources, node mobility, changes in path attenuation, and fluctuations in interference. By employing adaptive signaling techniques with Unequal Error Protection (UEP) to take advantage of the differences in the quality of service $(Q o S)$ requirements among different types of multimedia traffic, energy efficiency can be improved and also increase the data rate (spectral efficiency) over a fading channel, especially at low and moderate Carrier-to-Noise Ratio (CNR). This paper proposed a combination of curve fitting techniques that derives an exponential approximation to the average packet error rate (PER) probabilities as well as individual PER probabilities for asymmetrical phase-shift keying (PSK) and asymmetrical Quadrature Amplitude Modulation (QAM). Our design is both simpler and more robust than existing schemes.
\end{abstract}

\section{KEYWORDS}

Multiresolution Modulation, Adaptive Modulation, Mobile Ad Hoc Networks, Heterogeneous Traffic, Unequal Error Protection

\section{INTRODUCTION}

The quality of wireless links in an ad-hoc network is highly variable due to the mobility of radios, fluctuations in path attenuation, transmission impairments due to induced interference, and limited battery resources. Fixed transmission techniques are designed to accommodate worst case link margin channel conditions, therefore, results in suboptimal resource utilization. However, if the channel fade level is known by the transmitter shown in Fig. 1, the Shannon capacity can be approached by adapting the transmit power, data rate, and/or error coding relative to the channel fade level [1-2]. Researchers have shown SNR gains of up to $17 \mathrm{~dB}$ by using adaptive modulation techniques compared to that of using non-adaptive modulation in fading environments [3]. The objective of these adaptive signaling techniques is to enhance throughput by transmitting at an elevated data rate when the channel conditions are favorable.

Nearly all of the previously proposed adaptive signaling techniques are intended for systems wherein all of the data to be transmitted has the same quality of service (QOS) requirements. However, future generations of wireless communications networks will be required to support a multitude of services (voice, graphics, video, and data) with a wide variety of reliability requirements and data rates. Adaptive signaling techniques can be designed to exploit the differences in the quality of service requirements among dissimilar types of multimedia traffic. 


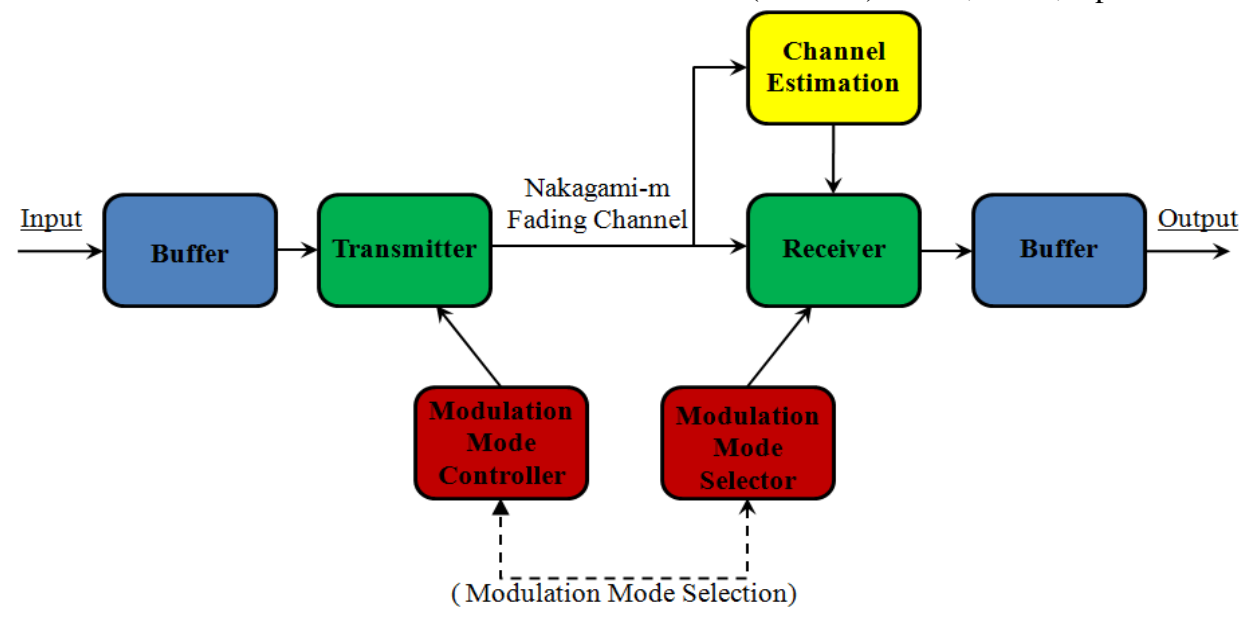

FEEDBACK CHANNEL

Figure 1. System Model

Recently, substantial research efforts have been dedicated to the integration of voice and data [4-5]. One study proposed adaptive hybrid binary phase shift keying (BPSK)/M-ary Amplitude Modulation (M-AM) as a solution to generate high probability of QoS [4]. This approach assigns the Quadrature $(Q)$ channel to voice with variable power BPSK and the In-phase $(I)$ channel to data with variable-rate M-AM. To exploit the time-varying nature of the channel, power is dynamically allocated between the $I$ and $Q$ channels. The power allocated to the $Q$ channel is just enough to satisfy the target BER for voice, $B R_{v}$, and the remaining power is allocated to the $I$ channel to support data with M-AM below the target $B R_{\mathrm{d}}$. Since M-ary quadrature amplitude modulation (M-QAM) is more spectrally efficient than the M-AM, an adaptive technique utilizing variable-rate uniform M-QAM was proposed in [5] for simultaneous transmission of voice and a single-class of data. However, due to the employment of uniform M-QAM signal constellations, the alphabet size is chosen such that, on average, both the voice and data are transmitted below the target BER for data, BER $_{d}$. Consequently, the voice receives unnecessary additional protection at the expense of the spectral efficiency (at low CNR) and outage probability for data.

The concept of transmitting two different classes of data (a basic message and an additional message) using an adaptive non-uniform PSK was proposed in [6]. In [6], both the size and shape (location of the message symbols) of the PSK constellations were proposed to adjust according to the CNR estimates. For this case, the non-uniform M-PSK constellations included two parts: coarse and fine. The coarse part was uniform M-PSK of alphabet size $N=M / 2$. Consequently, the BER of the coarse part is always approximately the same. The fine part consist of the least significant bit (LSB) in the symbol and can have a different probability of BER. One parameter $\theta$, the phase-offset ratio, was proposed to change according to the CNR estimate to increase the throughput for the additional message. In [7], the authors capitalize on the concept of generalized hierarchical (multi-resolution) QAM constellations and their BER expressions to propose a new technique which transmits voice and two different types of data below their respective target BERs. To exploit the time-varying nature of fading, the approach adapts not only the alphabet size but also the priority parameters (a set of parameters, instead of a single parameter as in [6]) of the hierarchical signal constellation, which control the relative BERs of different bit positions. Employing hierarchical M-QAM, the voice bit is transmitted in the LSB-position sub-channel (the least priority sub-channel) of the $Q$ channel. The remaining $\left(\log _{2} \mathrm{M}-1\right)$ sub-channels within the constellation are used for data transmission and allocated to different classes based on the selected priority parameters. 
International Journal of Wireless \& Mobile Networks (IJWMN) Vol. 4, No. 2, April 2012

Here, we consider a system in which multiple messages with different QOS requirements are transmitted simultaneously. Each block transmission may include one or more messages in each QOS class. In [6-7], the authors have propose possible solutions to this problem. However, both proposed designs have implementation deficiencies. In [6], the embedded gain is limited by the coarse part of the constellation since the BER for it is always approximately the same. In [7], a sophisticated optimization engine is required to determine the "optimal" shape of the M-QAM signal constellation. Such optimizations could results in non-unique / non-real solutions as well as long convergence times which are undesirable for real-time applications. In this paper, using curve fitting techniques we developed exponential approximation for both the exact average packet error rate (PER) probabilities as well as individual PER probabilities for asymmetrical phase-shift key (PSK) and asymmetrical quadrature amplitude (QAM) modulations. Also, we have developed a simple algorithm for determining the "optimum" phase-offset ratio when more than two UEP classes are considered.

\section{AdAPTIVE MUlTiResolution MOdUlation WiTH UEP}

\subsection{Background}

Previous research has established that the optimal broadcast/multicast scenarios are multiresolution in character due to the competitive nature of broadcast signaling. In multicast environments, the maximum information rate to one user is constrained by the rate of information sent to the other users [8]. However, the proposed conception of interlacing the "coarse" information within the "fine" information is broad in interpretation, and provides no boundaries on the domain in which embedding should be performed. Many researchers have since applied asymmetric signal constellation designs for digital speech transmission over mobile radio channels [9]-[11] and in terrestrial digital video broadcasting [12]-[15] under a joint source-channel coding framework. Others have used non-uniform 4-PSK to decrease the decoder complexity of trellis coded modulation [16]. Additional studies have also investigated the prospect for multicasting multimedia messages to numerous receivers with different capabilities [6], [17], and [18].

Contrary to all previous studies [8]-[18] (excluding [11], [15] and [23]) which are proficient in management of only two levels of UEP despite of the signal constellation size (which restricts the degrees of freedom as well as the data embedding gain), we have created a straightforward algorithm in [11] and [15] for establishing the "optimum" phase-offset ratio when more than two UEP classes are considered. Therefore, it is noteworthy that determining the "optimum" phase-offset ratio is not a trivial undertaking. This is particularly true when more than two UEP levels are employed. Furthermore, [17]-[21] have mainly concentrated on the signal design, predominantly disregarding cross-layer interactions, even though multicast communication also demands interaction with the upper layer protocols. In [22]-[23], we investigated the dilemma of designing a "matched" multi-resolution $M$-PSK modulation for improving the energy efficiency while concurrently unicasting/multicasting multiple classes of data each requiring a distinct QoS. In [24]-[25], we have also surveyed the effectiveness of multi-resolution modulation in realizing a passive (receiver-oriented) rate-adaptation mechanism without necessitating any feedback from the receiver to the sender for multimedia traffic.

As mentioned in section I, our proposed technique is more robust than [6] and much less complex than [7]. Also, unlike [6] and [7], our design seamlessly switches between M-PSK and M-QAM constellations. To realize our receiver-transmitter oriented rate adaptation strategy using M-PSK and M-QAM modulations, exponential functions were exploited for attaining curve fittings. The proposed receiver-transmitter rate adaptation strategy employs the average PER probability curve fitting approximation to establish which modulation scheme to apply for a specified PER requirement. The individual PER probability curve fitting approximations are then utilized to determine which bit of the asymmetric PSK or QAM constellation to assign to 
International Journal of Wireless \& Mobile Networks (IJWMN) Vol. 4, No. 2, April 2012

each distinct queue class so that the prescribed PER requirements are satisfied, as in Fig. 3. According to our design, the rate is to be adapted and maximized depending on the prevailing channel conditions (CNR) and the shape is to be adapted based upon the traffic QOS characteristics. In order to perform adaptive modulation, a readily invertible equation in terms of CNR, $\gamma$, is needed to determine the constellation size. In order to design an adaptive multiresolution modulation, a readily invertible expression is required to make decisions for both constellation size and shape.

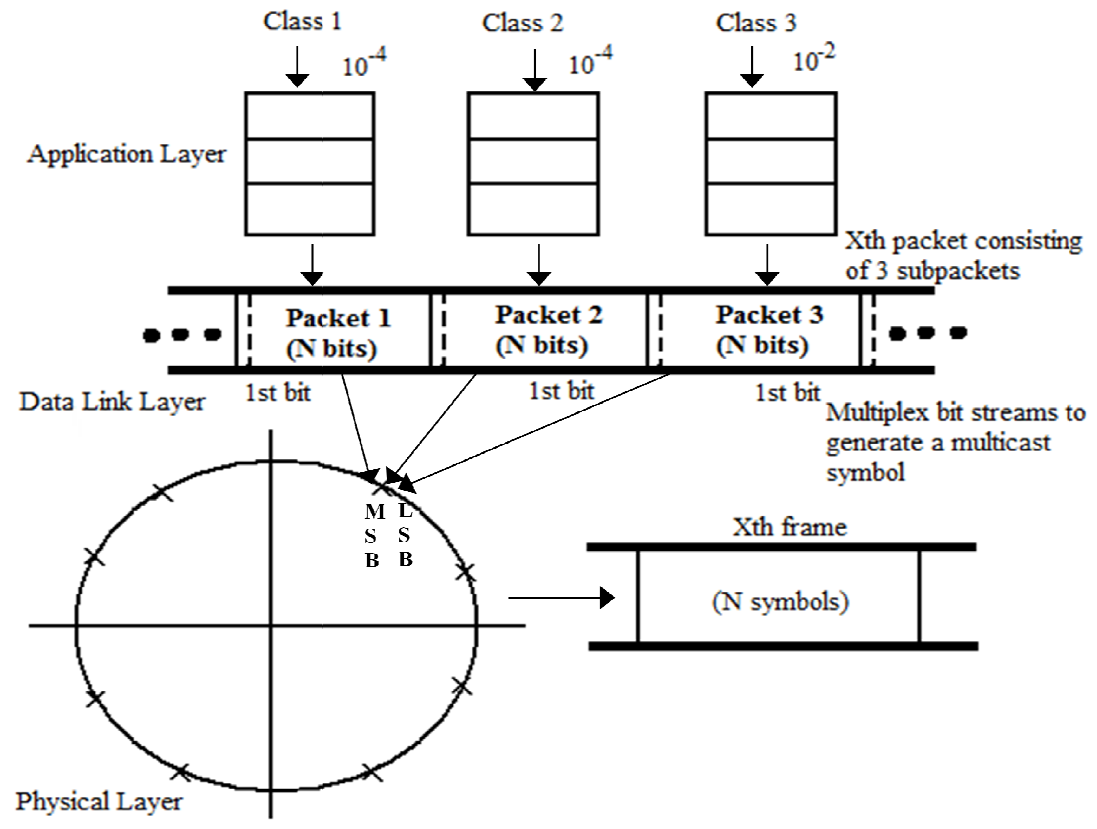

\section{-Leveraging the benefits of assymetric modulation at upper layers of protocol stack}

Figure 2. Implementation Design

\subsection{System Model}

Let's consider, the system model, in Fig. 1, which contains a single-transmitter and singlereceiver. The OSI layer implementation of our design is shown in Fig. 2. Our link adaptation strategy employs AMM at the PHY layer to maximize spectral efficiency based on prevailing link conditions and specified QoS requirements. At the application layer, QoS constraints are imposed through target PER requirements. At the physical layer, channel awareness is maintained through channel estimation techniques, such as pilot-based detection). Also, the processing unit at the PHY layer is a frame which is a collection of numerous transmitted symbols.

Seeing that the channel fluctuates from frame-to-frame, we opt to employ the Nakagami- $m$ block channel model to express $\gamma$ statistically, because it can apply a large class of fading channels with $m=1$ being equivalent to a Rayleigh fading channel. Additionally useful, there is a direct mapping between the Ricean factor $\mathrm{K}$ and the Nakagami fading parameter $m$. This permits the Nakagami- $m$ channel model to approximate Ricean channels very well. The SNR received per frame, $\gamma$, is a random variable with a Gamma probability density function:

$p_{\gamma}(\gamma)=\frac{m^{m} \gamma^{m-1}}{\bar{\gamma}^{m} \Gamma(m)} \exp \left(-\frac{m \gamma}{\bar{\gamma}}\right)$

where $\bar{\gamma}:=E\{\gamma\}$ is the average received SNR, 
International Journal of Wireless \& Mobile Networks (IJWMN) Vol. 4, No. 2, April 2012

$\Gamma(m):=\int_{0}^{\infty} t^{m-1} e^{-t} \mathrm{dt}$ is the Gamma function, and $m$ is the Nakagami fading parameter $(m \geq 1 / 2)$.

\section{Proposed Solution}

\subsection{Exponential Approximation}

By harmonizing the distinctive QoS requirements for multimedia sources to the shape of the multicast modulation, a significant embedding gain can be produced. Surprisingly, however, lack of discussion combining adaptive modulation and asymmetric constellations exists. This is attributed to the exact BER expressions found in [19]-[20] are not easily invertible with respect to CNR, $\gamma$.

Assuming bit-errors are uncorrelated, the PER $\left(\mathrm{P}_{\mathrm{B}}\right)$ can be related to the BER $\left(\mathrm{P}_{\mathrm{b}}\right)$ through

$\mathrm{P}_{\mathrm{B}}=1-\left(1-\mathrm{P}_{\mathrm{b}}\right)^{\mathrm{Np}}$

, where $\mathrm{N}_{\mathrm{p}}$ is the number of bits in each packet.

The precise BER equations for bit 1 and 2 of 16-QAM in terms of $\beta$ and $\gamma_{\mathrm{s}}$ are shown below in equation 3 and 4 respectively.

As for example, for 16-QAM :

- 4/16 QAM bit one:

$$
P_{b}^{Q A M}\left(16_{\gamma}^{\beta}, \beta, i_{1}\right)=\frac{1}{2}\left[\frac{1}{2} \operatorname{erfc}\left(\left(\beta^{-1}+1\right) \Omega\right)+\frac{1}{2} \operatorname{erfc}\left(\left(\beta^{-1}-1\right) \Omega\right)\right]
$$

- 4/16 QAM bit two:

$$
P_{b}^{Q A M}\left(16_{\gamma}^{\beta}, \beta, i_{2}\right)=\frac{1}{4}\left[2 \operatorname{erfc}(\Omega)-\operatorname{erfc}\left(\left(2 \beta^{-1}+1\right) \Omega\right)+\operatorname{erfc}\left(\left(2 \beta^{-1}-1\right) \Omega\right)\right]
$$

, where $\Omega=\sqrt{\frac{\gamma}{2\left(\beta^{-2}+1\right)}}$.

$\beta$ the phase offset ratio is as defined in Fig. 3 for Asymmetric 8-PSK and 4/16/64 QAM.

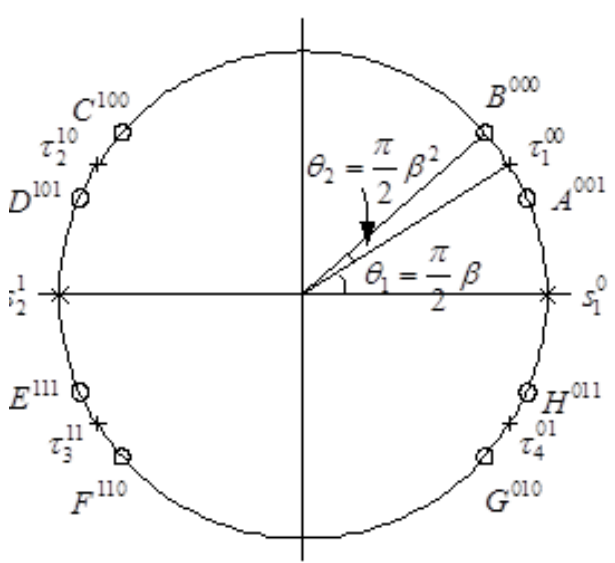

Figure 3a: Asymmetric 8-PSK Constellation

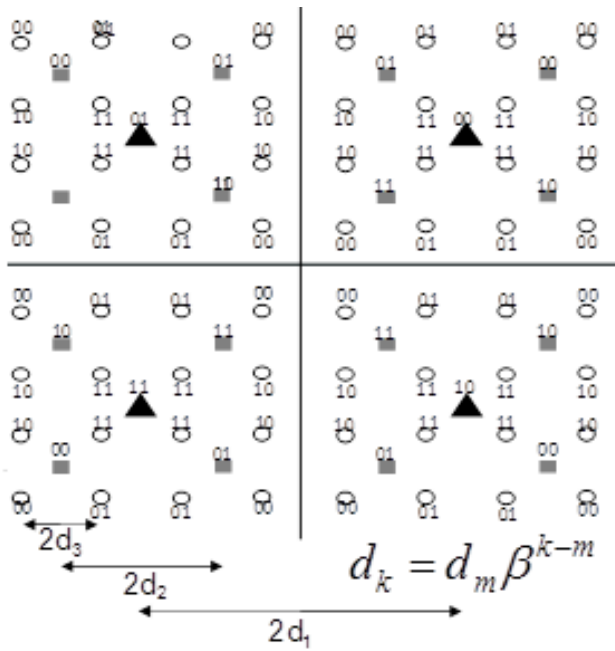

Figure 3b: 4/16/64 QAM Constellation

Figure 3. a) Asymmetric 8-PSK Constellation b) 4/16/64 QAM Constellation

As can be illustrated by equations (3) and (4), the BER expressions are not readily invertible, even for the symmetric case. This difficulty of having a quality readily invertible expression is 
International Journal of Wireless \& Mobile Networks (IJWMN) Vol. 4, No. 2, April 2012

compounded in the multiresolution modulation case. In this study, this is overcome by approximations developed using the exponential function [25]. Here, we pursue the same exact methods as shown in [25] to develop acceptably accurate approximations. To make this problem analytically tractable, we fix the ratio of angles for any subsequent levels of hierarchy to a constant (viz., $\theta_{k}=(\pi / 2) \beta^{k}$ ) so that only a single design parameter $\beta$ needs to be optimized as in $[6,25]$ (instead of manipulating $\log _{2} M-1$ variables) but without sacrificing the ability of higher order alphabets (i.e., denser signal constellations) to support a more flexible multimedia transmission. Our simplified asymmetric PSK and QAM constellations also revert to the uniform PSK case when $\beta=0.5$. We have also extended our previous efforts using exponential approximation for asymmetrical M-QAM and M-PSK and generated the curve fitting approximations for the average PER probability and individual PER for 4-PSK, 8-PSK, 16-PSK, 16-QAM, 64-QAM, and 256-QAM.

The exponential approximation equations used for M-QAM and M-PSK modulations in terms of $\beta$ and $\gamma_{\mathrm{s}}$ are illustrated below in equations 5 and 6 .

$\mathrm{P}_{\mathrm{B}}^{(\mathrm{i})}\left(\gamma_{\mathrm{s}}, \beta\right)=1 \quad$ if $\gamma_{\mathrm{s}}<\mathrm{d}_{\beta}^{(\mathrm{i})}$

$\mathrm{P}_{\mathrm{B}}^{(\mathrm{i})}\left(\gamma_{\mathrm{s}}, \beta\right)=\mathrm{a}_{\beta}^{(\mathrm{i})} \mathrm{e}^{-\mathrm{b}_{\beta}^{(\mathrm{i})} \gamma_{\mathrm{s}}}+\mathrm{c}_{\beta}^{(\mathrm{i})} \mathrm{e}^{-2 \mathrm{~b}_{\beta}^{(\mathrm{i})} \gamma_{\mathrm{s}}} \quad$ if $\quad \gamma_{\mathrm{s}} \geq \mathrm{d}_{\beta}^{(\mathrm{i})}$

- where $\mathrm{i}=1,2,3 \ldots, \log _{2} M, \beta$ is the phase-offset ratio, $\gamma_{\mathrm{s}}$ is the average $\mathrm{CNR}$, and $\mathrm{d}_{\beta}{ }^{(\mathrm{i})}=$ $\gamma_{\text {THRESHOLD }}$ which denotes the knee value of the plot.

- $\mathrm{a}_{\beta}{ }^{(\mathrm{i})}, \mathrm{b}_{\beta}{ }^{(\mathrm{i})}$, and $\mathrm{c}_{\beta}{ }^{(\mathrm{i})}$ are expressed in 3rd order polynomial of $\beta, \mathrm{p}_{3} \beta^{3}+\mathrm{p}_{2} \beta^{2}+\mathrm{p}_{1} \beta+\mathrm{p}_{0}$.

- $\mathrm{p}_{4}, \mathrm{p}_{3}, \mathrm{p}_{2}, \mathrm{p}_{1}$, and $\mathrm{p}_{0}$ are constants to be determined from the exponential approximation.

- $\mathrm{d}_{\beta}{ }^{(\mathrm{i})}$ is expressed by a 4 th order polynomial of $\beta$.

$a_{\beta}{ }^{(i)}, b_{\beta}{ }^{(i)}, c_{\beta}{ }^{(i)}$, and $d_{\beta}{ }^{(i)}$ are four parameters to be resolved such that the disparity between the exact PER and the estimate is minimized in the sense of mean square error. For this paper, we employed the Quasi-Newton BFGS algorithm to execute the curve fitting. The error tolerance of the utilized curve fitting algorithm was set to be $1 \mathrm{e}^{-10}$.

\subsection{Curve Fitting Results / Applications}

Using the exponential function, approximations were developed. For the exact curve, the complicated exact PER formulas were applied for $(\{0.1-0.5\} \beta \in)$ in an AWGN channel. Curve fitting results in Fig. 4 for exact and approximate PER probability (individual bits) for 16-QAM are illustrated. Curve fitting results for the exact and approximate average PER probability for different multi-resolution modulation schemes are illustrated in Fig. 5. From Fig. 4 and Fig.5, it can be shown that our invertible exponential expression yields a very tight approximation of the exact curves. Also, as shown in Fig. 4, as $\beta$ deviates from 0.5, the QOS disparity between $P_{B}^{1}\left(\gamma_{S}\right)$ and $P_{B}^{2}\left(\gamma_{S}\right)$ clearly increases. Consequently, classical symmetric modulation is well-suited for homogeneous traffic transmission where all bits have relatively the same QoS requirements. However, for heterogeneous traffic and multimedia applications where individual bits can have different QoS requirements, multiresolution modulation can significantly enhance spectral efficiency and system performance. 
International Journal of Wireless \& Mobile Networks (IJWMN) Vol. 4, No. 2, April 2012

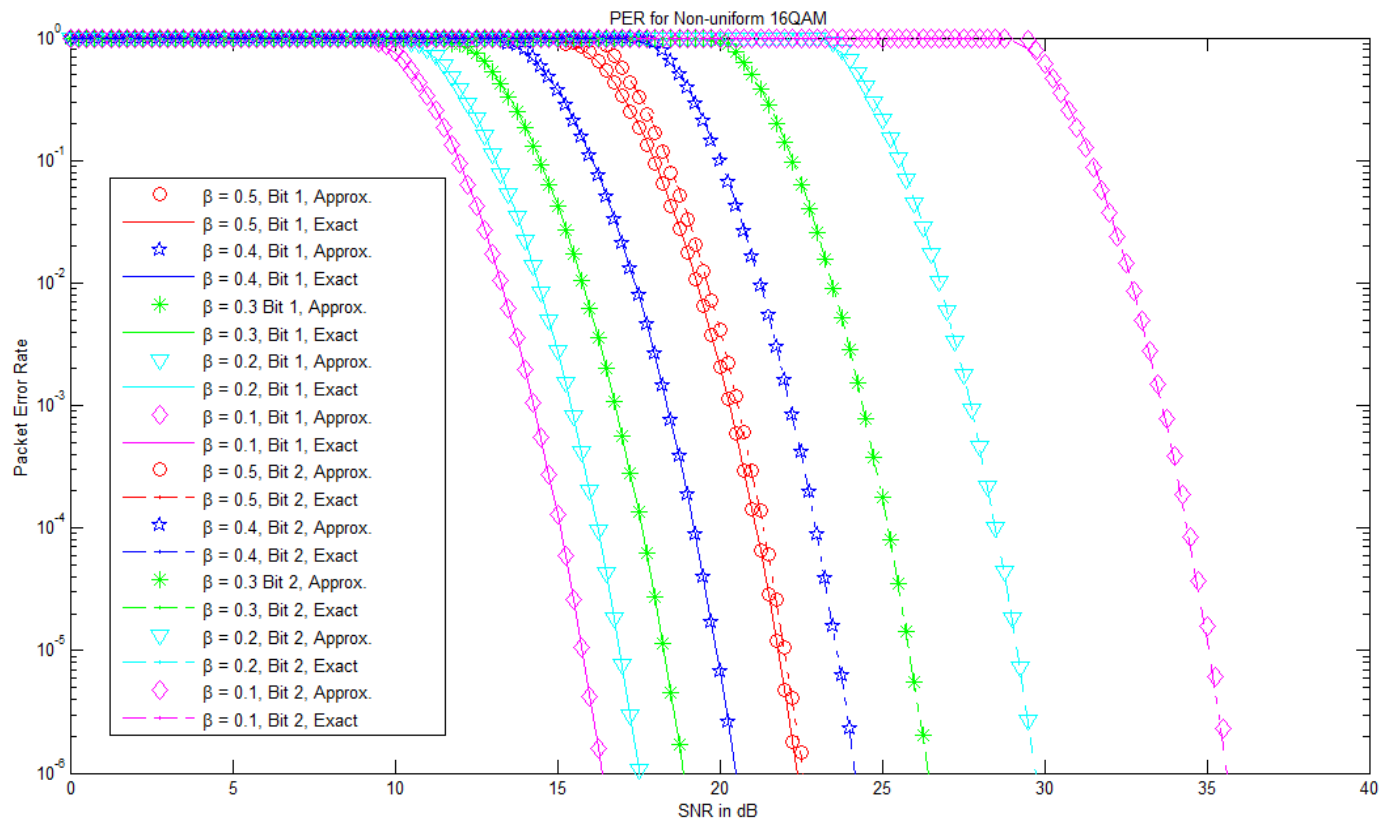

Figure 4. Exact and approximate PER for 16-QAM (individual bit class)

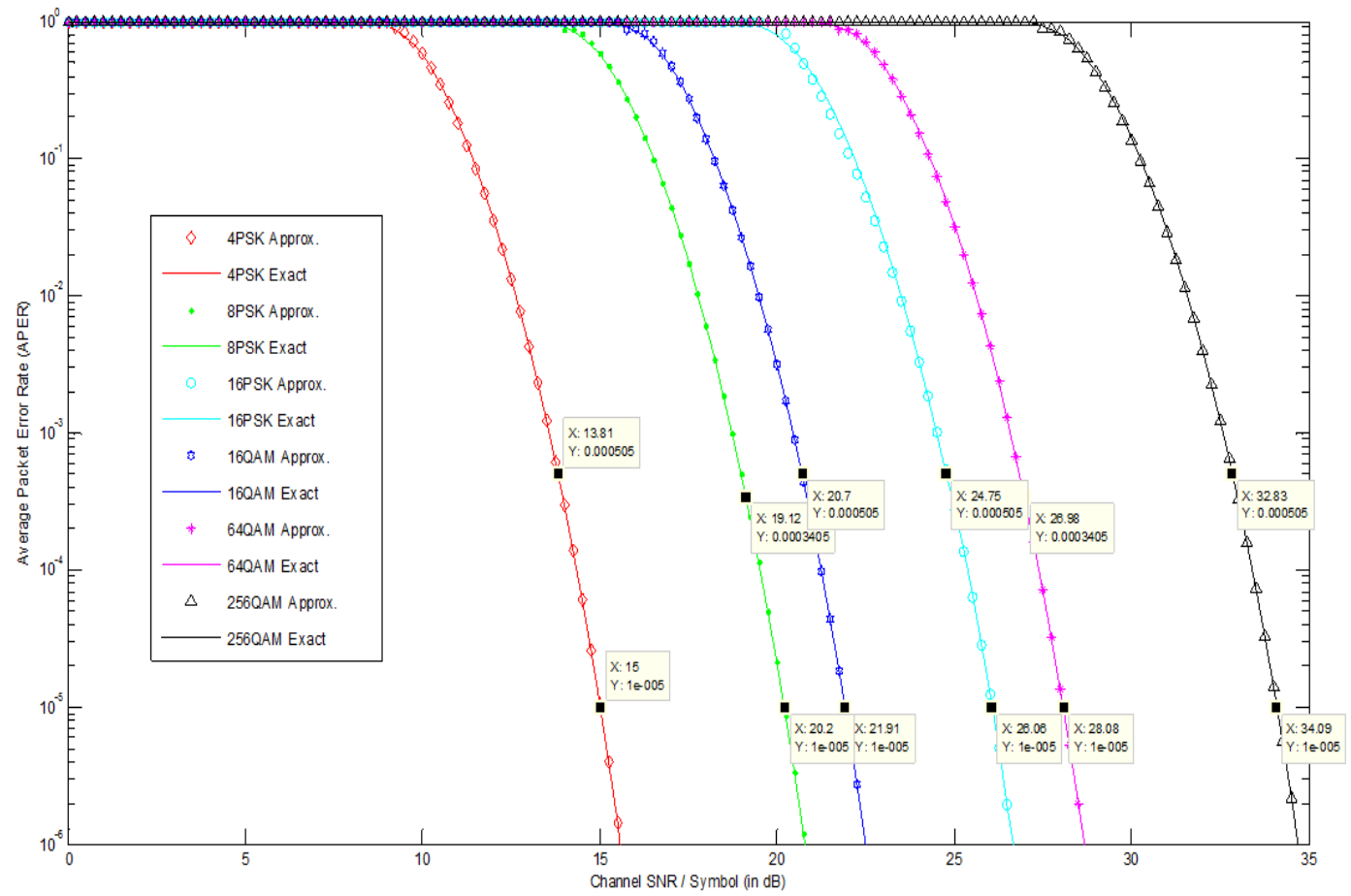

Figure 5: Exact and approximate average PER probability and the threshold values for both conventional and adaptive multiresolution schemes given the specified QOSs $10^{-5}$ and $10^{-3}$.

The polynomial coefficients $\left(\mathrm{p}_{4}, \mathrm{p}_{3}, \mathrm{p}_{2}, \mathrm{p}_{1}\right.$, and $\left.\mathrm{p}_{0}\right)$ for these figures are in table 1 and 2 . We also created curve fittings for 4-PSK, 8-PSK, 16-PSK, 64-QAM, and 256-QAM. A summary of polynomial coefficients for the average and individual PER probabilities using the exponential 
International Journal of Wireless \& Mobile Networks (IJWMN) Vol. 4, No. 2, April 2012 approximation for 4-PSK, 8-PSK, 16-PSK, 64-QAM, and 256-QAM are available through the appendix (Packet size $=1080$ bits/packet).

Table 1. POLYNOMIAL COEFFICIENTS FOR 16-QAM (INDIVIDUAL BIT CLASS) PROBABILITY

\begin{tabular}{|c|c|c|c|c|c|c|}
\hline & & $\mathbf{P}_{4}$ & $\mathbf{P}_{\mathbf{3}}$ & $\mathbf{P}_{2}$ & $\mathbf{P}_{1}$ & $\mathbf{P}_{\mathbf{0}}$ \\
\hline \multirow{4}{*}{1} & $\mathbf{a}_{\beta}{ }^{(1)}$ & N/a & -464.5364 & 472.3193 & -151.9469 & 83.8828 \\
\hline & $\mathbf{b}_{\beta}{ }^{(1)}$ & N/a & 0.1675 & 0.5434 & -1.1648 & 0.5296 \\
\hline & $\mathbf{c}_{\beta}{ }^{(1)}$ & $\mathrm{N} / \mathrm{a}$ & $2.0579 \mathrm{e}+04$ & $-2.0527 \mathrm{e}+04$ & $6.4391 e+03$ & $-1.9225 \mathrm{e}+03$ \\
\hline & $\mathbf{d}_{\beta}^{(1)}$ & 38.77 & -59.33 & 45.17 & -0.1344 & 8.955 \\
\hline \multirow{4}{*}{2} & $\mathbf{a}_{\beta}{ }^{(2)}$ & $\mathrm{N} / \mathrm{a}$ & 567.4087 & $-1.0637 \mathrm{e}+03$ & 498.5439 & 54.5480 \\
\hline & $\mathbf{b}_{\beta}^{(2)}$ & N/a & -0.4291 & 0.6580 & -0.0196 & $7.4264 \mathrm{e}-04$ \\
\hline & $\mathbf{c}_{\beta}{ }^{(2)}$ & $\mathrm{N} / \mathrm{a}$ & $-7.2657 e+04$ & $1.1728 \mathrm{e}+05$ & $-5.1231 e+04$ & $2.8093 e+03$ \\
\hline & $\mathbf{d}_{\beta}^{(2)}$ & 328.2000 & -553.8000 & 374.9000 & -136.9000 & 39.4100 \\
\hline
\end{tabular}

Table 2. POLYNOMIAL COEFFICIENTS FOR 16-QAM (AVERAGE BIT CLASS) PROBABILITY

\begin{tabular}{|l|l|l|l|l|l|}
\hline & $\mathbf{P}_{\mathbf{4}}$ & $\mathbf{P}_{\mathbf{3}}$ & $\mathbf{P}_{\mathbf{2}}$ & $\mathbf{P}_{\mathbf{1}}$ & $\mathbf{P}_{\mathbf{0}}$ \\
\hline $\mathbf{a}_{\boldsymbol{\beta}}$ & N/a & 0 & 0 & 0 & 101.4961 \\
\hline $\mathbf{b}_{\boldsymbol{\beta}}$ & N/a & 0 & 0 & 0 & 0.1038 \\
\hline $\mathbf{c}_{\boldsymbol{\beta}}$ & N/a & 0 & 0 & 0 & $-2.9007 \mathrm{e}+03$ \\
\hline $\mathbf{d}_{\boldsymbol{\beta}}$ & 649.4000 & -908.0000 & 514.1000 & -159.7000 & 39.9400 \\
\hline
\end{tabular}

Let's consider a circumstance whereby the channel necessitates maintaining two different types of traffic demanding two different QoS's. The QoS's respectively are $10^{-4}$ and $10^{-2}$. This is illustrated in Table 3.

Table 3. QOS demands for different modulation types a) QOSs $10^{-5} \& 10^{-3}$ b) QOSs $10^{-4} \& 10^{-2}$

\begin{tabular}{|c|c|c|}
\hline \multicolumn{3}{|c|}{ ***:To find the $C_{N R} R_{\mathrm{REQ}}$, the QOS demands must be known for PER $\mathrm{RVG}_{\mathrm{AVG}}$} \\
\hline For (4PSK, 16QAM) & For (8PSK, 64QAM) & For ((16PSK, 256QAM) \\
\hline $\begin{array}{c}\mathbf{P}_{\mathbf{B}}^{(\mathbf{1})} \leq \mathbf{1 0}^{-\mathbf{5}} \\
\mathbf{P}_{\mathbf{B}}^{(2)} \leq \mathbf{1 0}^{-\mathbf{3}} \\
\beta \in[0,0.5]\end{array}$ & $\begin{array}{l}\mathrm{P}_{\mathrm{B}}^{(1)} \leq 10^{-5} \\
\mathrm{P}_{\mathrm{B}}^{(2)} \leq 10^{-5} \\
\mathrm{P}_{\mathrm{B}}^{(3)} \leq 10^{-3} \\
{ }_{\beta} \in[0,0.5]\end{array}$ & $\begin{array}{l}\mathrm{P}_{\mathrm{B}}^{(1)} \leq 10^{-5} \\
\mathrm{P}_{\mathrm{B}}^{(2)} \leq 10^{-5} \\
\mathrm{P}_{\mathrm{B}}^{(3)} \leq 10^{-3} \\
\mathrm{P}_{\mathrm{B}}^{(4)} \leq 10^{-3} \\
{ }_{\beta} \in[0,0.5]\end{array}$ \\
\hline $10^{-5}+10^{-3}$ & $10^{-5}+10^{-5}+10^{-3}$ & $10^{-5}+10^{-5}+10^{-3}+10^{-3}$ \\
\hline $\begin{array}{c}2 \\
=0.000505\end{array}$ & $\begin{array}{r}3 \\
=0.00034\end{array}$ & $\begin{array}{l}4 \\
=0.000505\end{array}$ \\
\hline
\end{tabular}

(a)

\begin{tabular}{|c|c|c|}
\hline $\begin{array}{l}\text { For (4PSK, } \\
\text { 16QAM) }\end{array}$ & For (8PSK, 64QAM) & For ((16PSK, 256QAM) \\
\hline $\begin{array}{c}\mathbf{P}_{\mathbf{B}}^{(\mathbf{1})} \leq \mathbf{1 0}^{-\mathbf{4}} \\
\mathbf{P}_{\mathbf{B}}^{(2)} \leq \mathbf{1 0}^{-\mathbf{2}} \\
\beta \in[0,0.5]\end{array}$ & $\begin{array}{l}\mathrm{P}_{\mathrm{B}}^{(1)} \leq 10^{-4} \\
\mathrm{P}_{\mathrm{B}}^{(2)} \leq 10^{-4} \\
\mathrm{P}_{\mathrm{B}}^{(3)} \leq 10^{-2} \\
\quad{ }_{\beta} \in[0,0.5]\end{array}$ & $\begin{array}{l}\mathrm{P}_{\mathrm{B}}^{(1)} \leq 10^{-4} \\
\mathrm{P}_{\mathrm{B}}^{(2)} \leq 10^{-4} \\
\mathrm{P}_{\mathrm{B}}^{(3)} \leq 10^{-2} \\
\mathrm{P}_{\mathrm{B}}^{(4)} \leq 10^{-2}\end{array}$ \\
\hline
\end{tabular}


International Journal of Wireless \& Mobile Networks (IJWMN) Vol. 4, No. 2, April 2012

\begin{tabular}{|c|c|c|}
\hline & & ${ }_{\beta} \in[0,0.5]$ \\
\hline$\frac{\mathbf{1 0}^{-4}+\mathbf{1 0}^{-\mathbf{2}}}{2}$ & $\frac{10^{-4}+10^{-4}+10^{-2}}{3}$ & $\frac{10^{-4}+10^{-4}+10^{-2}+10^{-2}}{4}$ \\
$=\mathbf{0 . 0 0 5 0 5}$ & $=0.0034^{3}$ & $=0.00505$ \\
\hline
\end{tabular}

(b)

Depending on the channel condition, the scheme should be able of determining the best modulation scheme to employ in order to meet the required QoS. This can be done either by a labor-intensive method (plotting the curve using the exact equation, and manually establishing the switching threshold values through graphical analysis for different modulation schemes), or by utilizing the invertible expression to forecast the $\gamma_{\mathrm{REQ}}$. The manual technique is rigorous and cannot be automated. Thus, the invertible expression in eqn. 7 , which is the inversion of eqn. 6 , supplies an extremely straightforward and simple approach for determining the switching threshold values for each.

$y_{\beta}^{(i)}=\frac{\left(-a_{\beta}^{(i)}+\sqrt{\left(a_{\beta}^{(i)}\right)^{2}+4 c_{\beta}^{(i)} P_{B}^{(i)}}\right)}{2 c_{\beta}^{(i)}}$

$\gamma_{\mathrm{req}}^{(\mathrm{i})}(\beta)=-\frac{1}{\mathrm{~b}_{\beta}^{(\mathrm{i})}} \ln \mathrm{y}_{\beta}^{(\mathrm{i})}, \quad i=1,2,3, \ldots \log _{2} M$

Employing our approach, the curve for the average PER rate is necessary for inter-modulation threshold determination. The required QoS for the average PER is the average of the individual QOS's. For the case where there are two distinct class, the QOS requirements would be $\left(10^{-4}+\right.$ $10^{-2}$ ) / 2. After determining the mandatory CNRs that designates which modulation scheme to exploit for a particular range of channel conditions, we also must establish the CNR threshold values to be exploited within each modulation schemes in order to cater to the QoS requirements for the individual bits. These CNR threshold values are referred to as intramodulation thresholds. For both the cases (average and individual), the threshold values are listed in Tables $5 \& 6$ respectively. Within each modulation scheme, we decide to have the most rigorous provision for the first bit and the next condition for the next bit after that. Following this, we use $10^{-4}$ for bit 1 and $10^{-2}$ for bit 2 , for the case of 4/16 QAM modulation scheme. Conversely, for the usage of 4/16/64 QAM modulation scheme, we opt to have $10^{-4}$ for bit $1,10^{-}$ ${ }^{4}$ for bit 2 and $10^{-2}$ for bit 3 .

\subsection{Optimum Phase-Offset Ratio Algorithm}

To facilitate determining the optimum $\beta$ value for each modulation scheme, we should decide on the $\beta$ value that results in the minimum of the maximum $\gamma_{\text {req }}^{i}$.

$\left.\arg \min _{\beta} \max _{i}\left\{\gamma_{\text {req }}^{i}\right\}\right\}$

For the particular case of 4/16/64 QAM, the QoS's are defined as,

- $\mathrm{P}_{\mathrm{B}}^{(1)} \leq 10^{-4}$

- $\mathrm{P}_{\mathrm{B}}^{(2)} \leq 10^{-4}$

- $\mathrm{P}_{\mathrm{B}}{ }^{(3)} \leq 10^{-2}$

$\beta \in(0,0.5], i \in\{1,2,3\}$. 
International Journal of Wireless \& Mobile Networks (IJWMN) Vol. 4, No. 2, April 2012

\section{COMPUTATIONAL RESULTS}

Acquiring the optimum $\beta$ value for different modulation scheme guarantees that each modulation scheme maximizes its capability based on the specified QoS requirements. It is also worth noting that this is attainable with the aid of the invertible expression found in eqn. 7, which is a direct application of the curve fitting process. The optimum phase-offset ratios, $\beta$, for different modulations with respect to QOS demands are in Table 4.

Table 4. Optimum beta value for different modulations a) QOSs $10^{-5} \& 10^{-3}$ b) QOSs $10^{-4} \& 10^{-2}$

\begin{tabular}{|c|c|}
\hline Modulation & Optimum Beta \\
\hline 4PSK & 0.450 \\
\hline 8PSK & 0.485 \\
\hline 16PSK & 0.490 \\
\hline 16QAM & 0.465 \\
\hline 64QAM & 0.465 \\
\hline 256QAM & 0.490 \\
\hline
\end{tabular}

(a)

\begin{tabular}{|c|c|}
\hline Modulation & Optimum Beta \\
\hline 4PSK & 0.440 \\
\hline 8PSK & 0.485 \\
\hline 16PSK & 0.485 \\
\hline 16QAM & 0.455 \\
\hline 64QAM & 0.460 \\
\hline 256QAM & 0.485 \\
\hline
\end{tabular}

(b)

The assorted CNR threshold, $\gamma_{\mathrm{REQ}}$, values obtained for inter-modulation schemes are listed in Table 5, while the values obtained for intra-modulation switching thresholds (the CNR values at which the requirements for each individual bits are being accommodated within different modulation schemes) are revealed in Table 6.

Table 5. Threshold values (in $\mathrm{dB}$ ) for the Inter-modulation scheme a) QOSs $10^{-5} \& 10^{-3} \mathrm{~b}$ ) QOSs $10^{-4} \& 10^{-2}$

\begin{tabular}{|c|c|c|c|c|c|c|}
\hline Modulation & 4PSK & 8PSK & 16PSK & 16QAM & 64QAM & 256QAM \\
\hline Conventional & $\mathbf{1 5 . 0 0}$ & $\mathbf{2 0 . 2 0}$ & $\mathbf{2 6 . 0 6}$ & $\mathbf{2 1 . 9 1}$ & $\mathbf{2 8 . 0 8}$ & $\mathbf{3 4 . 0 9}$ \\
\hline Adaptive & $\mathbf{1 3 . 8 1}$ & $\mathbf{1 9 . 1 2}$ & $\mathbf{2 4 . 7 5}$ & $\mathbf{2 0 . 7 0}$ & $\mathbf{2 6 . 9 8}$ & $\mathbf{3 2 . 8 3}$ \\
\hline
\end{tabular}

(a)

\begin{tabular}{|c|c|c|c|c|c|c|}
\hline Modulation & 4PSK & 8PSK & 16PSK & 16QAM & 64QAM & 256QAM \\
\hline Conventional & 14.34 & 19.53 & 25.36 & 21.24 & 27.39 & 33.39 \\
\hline Adaptive & $\mathbf{1 2 . 9 3}$ & $\mathbf{1 8 . 2 6}$ & $\mathbf{2 3 . 8 1}$ & $\mathbf{1 9 . 8 0}$ & $\mathbf{2 6 . 0 9}$ & $\mathbf{3 1 . 8 9}$ \\
\hline
\end{tabular}

(b) 
International Journal of Wireless \& Mobile Networks (IJWMN) Vol. 4, No. 2, April 2012

Table 6. Threshold values (in $\mathrm{dB}$ ) for the Intra-modulation scheme a) QOSs $10^{-5} \& 10^{-3} \mathrm{~b}$ ) QOSs $10^{-4} \& 10^{-2}$

\begin{tabular}{|c|c|c|c|c|c|c|}
\hline Modulation & $\begin{array}{c}\text { Bit } \\
\text { Class }\end{array}$ & $\alpha=\beta=0.3$ & $\alpha=\beta=0.4$ & $\alpha=\beta=0.5$ & $\alpha=\beta=0 p$ timum & $\mathbf{Q O S}_{\text {PER }_{\text {AVG }}}$ \\
\hline \multirow{2}{*}{ 4PSK } & Bit 1 & 12.99 & 13.83 & 15.00 & 14.37 & $10^{-5}$ \\
\hline & Bit 2 & 17.42 & 15.17 & 13.57 & 14.31 & $10^{-3}$ \\
\hline \multirow{3}{*}{ 8PSK } & Bit 1 & 13.55 & 15.71 & 20.15 & 19.23 & $10^{-5}$ \\
\hline & Bit 2 & 21.59 & 20.48 & 20.15 & 20.15 & $10^{-5}$ \\
\hline & Bit 3 & 27.58 & 22.67 & 18.87 & 19.38 & $10^{-3}$ \\
\hline \multirow{4}{*}{ 16PSK } & Bit 1 & 13.66 & 16.69 & 25.80 & 24.11 & $10^{-5}$ \\
\hline & Bit 2 & 22.55 & 22.88 & 25.80 & 25.32 & $10^{-5}$ \\
\hline & Bit 3 & 30.40 & 26.76 & 24.75 & 24.67 & $10^{-3}$ \\
\hline & Bit 4 & 38.01 & 30.53 & 24.75 & 25.28 & $10^{-3}$ \\
\hline \multirow{2}{*}{ 16QAM } & Bit 1 & 18.29 & 19.89 & 21.80 & 21.10 & $10^{-5}$ \\
\hline & Bit 2 & 24.40 & 22.17 & 20.56 & 21.07 & $10^{-3}$ \\
\hline \multirow{3}{*}{ 64QAM } & Bit 1 & 19.32 & 22.49 & 27.84 & 25.56 & $10^{-5}$ \\
\hline & Bit 2 & 28.78 & 27.95 & 28.04 & 27.91 & $10^{-5}$ \\
\hline & Bit 3 & 34.89 & 30.22 & 26.79 & 27.88 & $10^{-3}$ \\
\hline \multirow{4}{*}{ 256QAM } & Bit 1 & 19.53 & 23.66 & 33.70 & 31.94 & $10^{-5}$ \\
\hline & Bit 2 & 29.78 & 30.46 & 33.91 & 33.37 & $10^{-5}$ \\
\hline & Bit 3 & 37.73 & 34.41 & 32.60 & 32.72 & $10^{-3}$ \\
\hline & Bit 4 & 45.35 & 38.20 & 32.86 & 33.33 & $10^{-3}$ \\
\hline
\end{tabular}

(a)

\begin{tabular}{|c|c|c|c|c|c|c|}
\hline Modulation & $\begin{array}{c}\text { Bit } \\
\text { Class }\end{array}$ & $\alpha=\beta=0.3$ & $\alpha=\beta=0.4$ & $\alpha=\beta=0.5$ & $\alpha=\beta=0 p t i m u m$ & $\mathbf{Q O S}_{\mathrm{PER}_{\mathrm{AI}}}$ \\
\hline \multirow{2}{*}{ 4PSK } & Bit 1 & 12.33 & 13.17 & 14.34 & 13.60 & $10^{-4}$ \\
\hline & Bit 2 & 16.48 & 14.24 & 12.63 & 13.53 & $10^{-2}$ \\
\hline \multirow{3}{*}{ 8PSK } & Bit 1 & 12.86 & 15.02 & 19.48 & 18.53 & $10^{-4}$ \\
\hline & Bit 2 & 20.90 & 19.79 & 19.46 & 19.46 & $10^{-4}$ \\
\hline & Bit 3 & 26.64 & 21.71 & 17.96 & 18.47 & $10^{-2}$ \\
\hline \multirow{4}{*}{ 16PSK } & Bit 1 & 12.96 & 15.97 & 25.08 & 22.67 & $10^{-4}$ \\
\hline & Bit 2 & 21.83 & 22.16 & 25.08 & 24.37 & $10^{-4}$ \\
\hline & Bit 3 & 29.40 & 25.76 & 23.81 & 23.76 & $10^{-2}$ \\
\hline & Bit 4 & 37.07 & 29.59 & 23.81 & 24.60 & $10^{-2}$ \\
\hline \multirow{2}{*}{ 16QAM } & Bit 1 & 17.59 & 19.20 & 21.11 & 20.21 & $10^{-4}$ \\
\hline & Bit 2 & 23.46 & 21.23 & 19.62 & 20.29 & $10^{-2}$ \\
\hline \multirow{3}{*}{ 64QAM } & Bit 1 & 18.59 & 21.76 & 27.11 & 24.55 & $10^{-4}$ \\
\hline & Bit 2 & 28.08 & 27.26 & 27.34 & 27.21 & $10^{-4}$ \\
\hline & Bit 3 & 33.95 & 29.29 & 25.85 & 27.11 & $10^{-2}$ \\
\hline \multirow{4}{*}{ 256QAM } & Bit 1 & 18.78 & 22.90 & 32.94 & 30.41 & $10^{-4}$ \\
\hline & Bit 2 & 29.05 & 29.74 & 33.19 & 32.39 & $10^{-4}$ \\
\hline & Bit 3 & 36.73 & 33.41 & 31.60 & 31.79 & $10^{-2}$ \\
\hline & Bit 4 & 44.41 & 37.26 & 31.92 & 32.64 & $10^{-2}$ \\
\hline
\end{tabular}

(b) 
International Journal of Wireless \& Mobile Networks (IJWMN) Vol. 4, No. 2, April 2012

When mode $n$ is employed, each symbol transmitted will contain $R_{n}=\log _{2}\left(M_{n}\right)$ information bits. We presume a Nyquist pulse shaping filter with bandwidth, $\mathrm{B}=1 / \mathrm{T}_{\mathrm{s}}$, where $\mathrm{T}_{\mathrm{s}}$ is the symbol rate. For the adaptive multiresolution scheme, the average spectral efficiency (bit rate per unit bandwidth) can be written as shown in equation (10).

$$
\begin{aligned}
\eta_{\text {adap }}= & 0 \int_{\gamma_{T 1}}^{\gamma_{4 p 1}} f_{\gamma}(\gamma) \delta_{\gamma}+1 \int_{\gamma_{4 p 1}}^{\gamma_{4 p 2}} f_{\gamma}(\gamma) \delta_{\gamma}+2 \int_{\gamma_{4 p 2}}^{\gamma_{T 2}} f_{\gamma}(\gamma) \delta_{\gamma}+0 \int_{\gamma_{T 2}}^{\gamma_{8 p 1}} f_{\gamma}(\gamma) \delta_{\gamma} \\
& +1 \int_{\gamma_{8 p 1}}^{\gamma_{8 p 2}} f_{\gamma}(\gamma) \delta_{\gamma}+2 \int_{\gamma_{8 p 2}}^{\gamma_{8 p 3}} f_{\gamma}(\gamma) \delta_{\gamma}+3 \int_{\gamma_{8 p 3}}^{\gamma_{T 3}} f_{\gamma}(\gamma) \delta_{\gamma}+0 \int_{\gamma_{T 3}}^{\gamma_{16 Q 1}} f_{\gamma}(\gamma) \delta_{\gamma} \\
& +2 \int_{\gamma_{16 Q 1}}^{\gamma_{16 Q 2}} f_{\gamma}(\gamma) \delta_{\gamma}+4 \int_{\gamma_{16 Q 2}}^{\gamma_{T 4}} f_{\gamma}(\gamma) \delta_{\gamma}+0 \int_{\gamma_{T 4}}^{\gamma_{16 p 1}} f_{\gamma}(\gamma) \delta_{\gamma} \\
& +1 \int_{\gamma_{16 p 1}}^{\gamma_{16 p 2}} f_{\gamma}(\gamma) \delta_{\gamma}+2 \int_{\gamma_{16 p 2}}^{\gamma_{16 p 3}} f_{\gamma}(\gamma) \delta_{\gamma}+3 \int_{\gamma_{16 p 3}}^{\gamma_{16 p 4}} f_{\gamma}(\gamma) \delta_{\gamma} \\
& +4 \int_{\gamma_{16 p 4}}^{\gamma_{T 5}} f_{\gamma}(\gamma) \delta_{\gamma}+0 \int_{\gamma_{T 5}}^{\gamma_{64 Q 1}} f_{\gamma}(\gamma) \delta_{\gamma}+2 \int_{\gamma_{64 Q 1}}^{\gamma_{642}} f_{\gamma}(\gamma) \delta_{\gamma} \\
& +4 \int_{\gamma_{64 Q 2}}^{\gamma_{64 Q 3}} f_{\gamma}(\gamma) \delta_{\gamma}+6 \int_{\gamma_{64 Q 3}}^{\gamma_{T 6}} f_{\gamma}(\gamma) \delta_{\gamma}+0 \int_{\gamma_{T 6}}^{\gamma_{256 Q 1}} f_{\gamma}(\gamma) \delta_{\gamma} \\
& +2 \int_{\gamma_{256 Q 1}}^{\gamma_{256 Q 2}} f_{\gamma}(\gamma) \delta_{\gamma}+4 \int_{\gamma_{256 Q 2}}^{\gamma_{256 Q 3}} f_{\gamma}(\gamma) \delta_{\gamma}+6 \int_{\gamma_{256 Q 3}}^{\gamma_{256 Q 4}} f_{\gamma}(\gamma) \delta_{\gamma} \\
& +8 \int_{\gamma_{256 Q 4}}^{\infty} f_{\gamma}(\gamma) \delta_{\gamma}
\end{aligned}
$$

where $\gamma_{\mathrm{T} 1}, \gamma_{\mathrm{T} 2}, \gamma_{\mathrm{T} 3}, \gamma_{\mathrm{T} 4}, \gamma_{\mathrm{T} 5}$, and $\gamma_{\mathrm{T} 6}$, are the adaptive scheme's inter-modulation threshold values for 4PSK, 8PSK, 16QAM, 16PSK, 64QAM, and 256QAM respectively. $\gamma_{4 \mathrm{P} 1}$, and $\gamma_{4 \mathrm{P} 2}$, are the intra modulation threshold values for 4PSK. In a similar manner, $\gamma_{16 \mathrm{Q} 1}$ and $\gamma_{16 \mathrm{Q} 2}$, are the intra modulation threshold values for 16QAM. Equation (10) is applicable in a situation whereby $\gamma_{\mathrm{T} 1}$ $<\gamma_{4 \mathrm{P} 1}<\gamma_{4 \mathrm{P} 2}<\gamma_{\mathrm{T} 2}<\gamma_{8 \mathrm{P} 1}<\gamma_{8 \mathrm{P} 2}<\gamma_{8 \mathrm{P} 3}<\gamma_{\mathrm{T} 3}<\gamma_{16 \mathrm{Q} 1}<\gamma_{16 \mathrm{Q} 2}<\gamma_{\mathrm{T} 4}<\gamma_{16 \mathrm{P} 1}<\gamma_{16 \mathrm{P} 2}<\gamma_{16 \mathrm{P} 3}<\gamma_{16 \mathrm{P} 4}<\gamma_{\mathrm{T} 5}<$ $\gamma_{64 \mathrm{Q} 1}<\gamma_{64 \mathrm{Q} 2}<\gamma_{64 \mathrm{Q} 3}<\gamma_{\mathrm{T} 6}<\gamma_{256 \mathrm{Q} 1}<\gamma_{256 \mathrm{Q} 2}<\gamma_{256 \mathrm{QP} 3}<\gamma_{256 \mathrm{QP} 4}$

Figures 6 and 7 show the spectral efficiency using under Nakagami block fading channel conditions, while Fig. 8 and 9 show the spectral efficiency as a function of the Nakagami fading parameter, $\mathrm{m}$, which is equivalent to the order of diversity. The results are shown for different $\beta$ values including normal transmission in which $\beta=0.5$ and the optimum $\beta$ value.

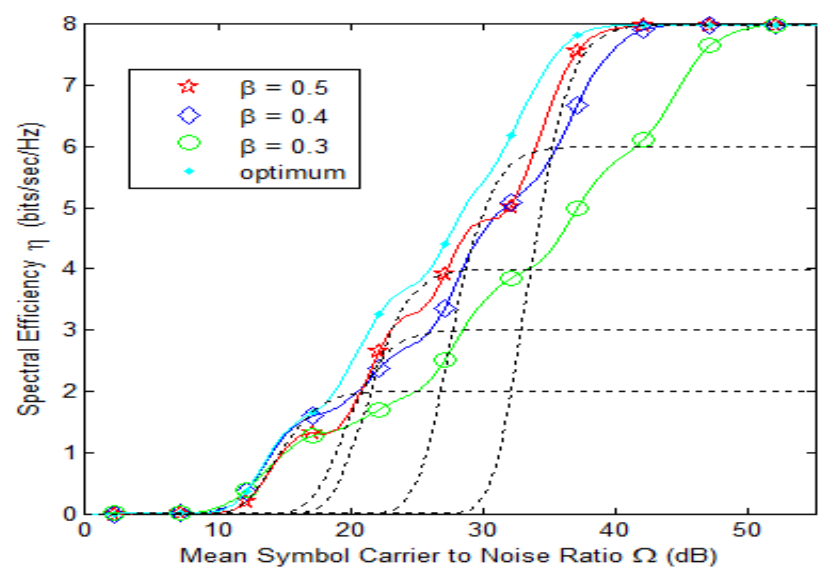

Figure 6. Spectral Efficiency for different beta values using QOSs $10^{-4} \& 10^{-2}$ (nakagami-m=3) 
International Journal of Wireless \& Mobile Networks (IJWMN) Vol. 4, No. 2, April 2012

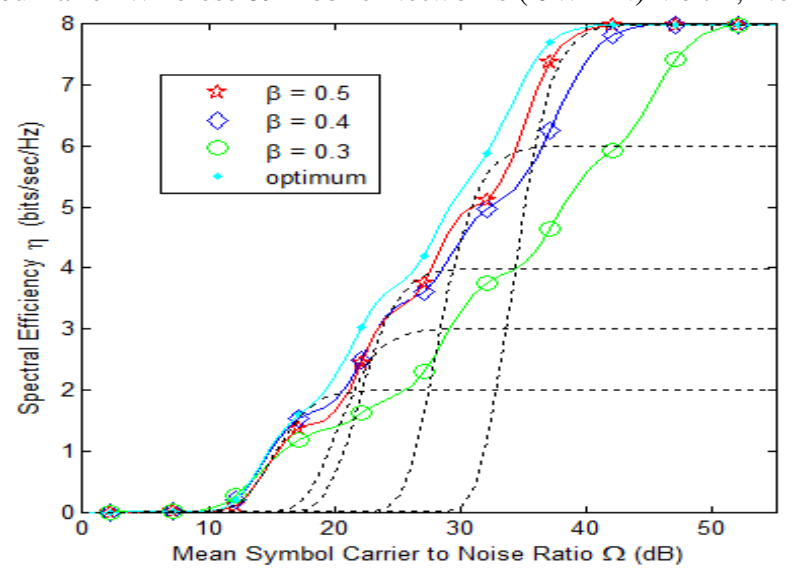

Figure 7. Spectral Efficiency for different beta values using QOSs $10^{-5} \& 10^{-3}$ (nakagami-m=3)

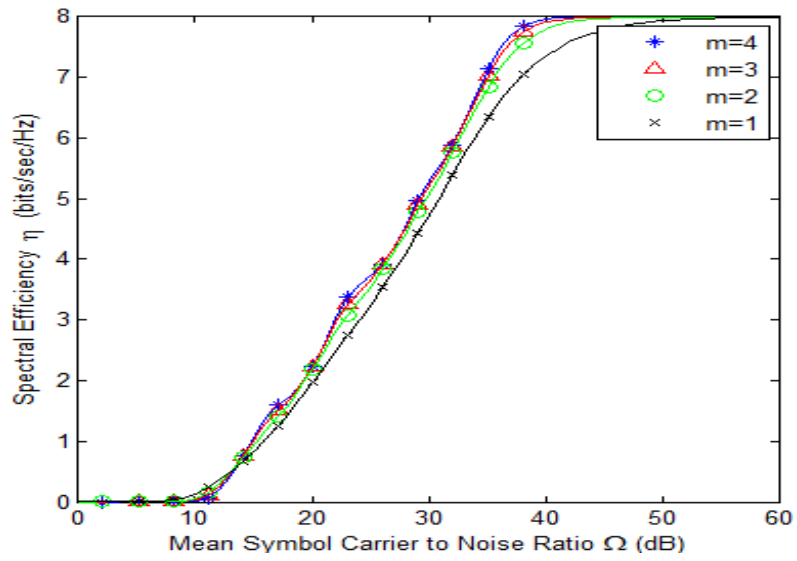

Figure 8. Spectral Efficiency for different nakagami-m fading parameter using QOSs $10^{-5} \& 10^{-3}$

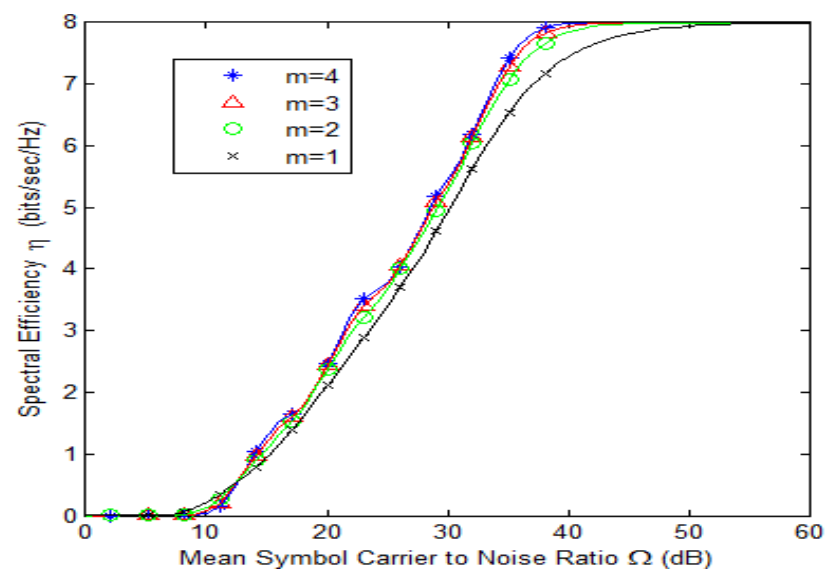

Figure 9. Spectral Efficiency for different nakagami-m fading parameter using QOSs $10^{-4} \& 10^{-2}$

Figures 10 and 11 show the results obtained for the average probabilty of packet error rate using adaptive multiresolution modulation techniques based on the specified QOSs under Nakagami fading channel conditions. The results were obtained by using the switching threshold values in Table 4 and 5. 
International Journal of Wireless \& Mobile Networks (IJWMN) Vol. 4, No. 2, April 2012

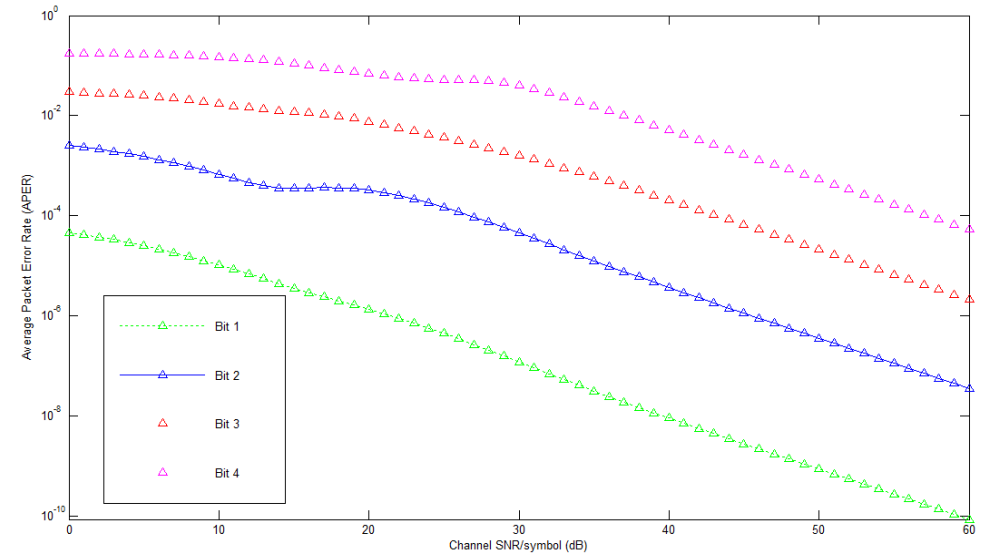

Figure 10. Average PER using $\mathrm{m}=1, \beta=0.45$, and QOSs $10^{-5}$ and $10^{-3}$

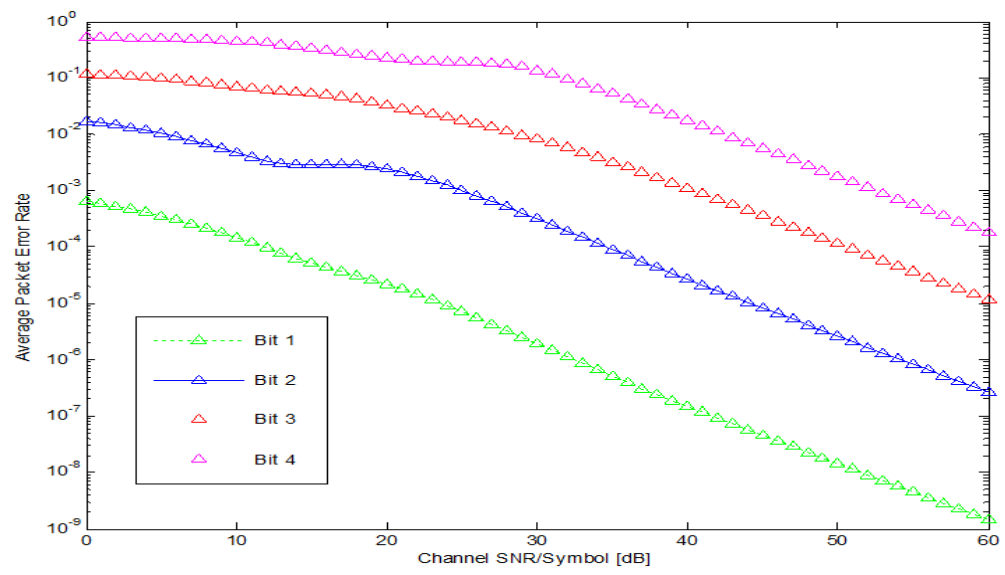

Figure 11. Average PER using $m=1, \beta=0.45$, and QOSs $10^{-4}$ and $10^{-2}$

From Tables 5 \& 6, it is apparent that our multiresolution modulation technique in comparison to the conventional scheme reduces the (inter-modulation and intra-modulation) switching threshold values for each case. These decreased switching thresholds aid in facilitating higher spectral efficiency.

From fig(s). 6 and 7, we note that, if phase-offset ratio $\beta$ is fixed, conventional symmetrical modulation $(\beta=0.5)$ would be best in the high SNR / CNR range. However, for low and moderate SNR / CNR, the multiresolution modulation proposed is more advantageous. This is because of the UEP facilitated through asymmetric modulation. Since, standard symmetric modulations give equal priority to each bit within the symbol, channel conditions affect each bit equally. However, since multiresolution modulation maps more the important bits to higher priority positions within the transmitted symbol, the bits are unequally protected. Thus, in the case that we receive and an erroneous symbol, we can recover the more important bits. As $\beta$ is reduced, the unequal protection disparity becomes greater amongst the bit classes. Consequently, if $\beta$ was fixed, $\beta=0.3$ would perform best in the low SNR / CNR range, $\beta=0.4$ would perform best in the moderate SNR / CNR range, and $\beta=0.5$ would perform best in the high SNR / CNR range. However, employing our algorithm (9) for determining the optimum $\beta$ for the specified QOS's, we acquired the best spectral efficiency across the low. moderate, and high SNR / CNR ranges.

Figures 10 and 11 illustrate the average PER for each bit class based on the prescribed QoS constraints. From figs. 10 and 11, it is obvious that the bit 1 (the most significant bit) is more 
International Journal of Wireless \& Mobile Networks (IJWMN) Vol. 4, No. 2, April 2012

protected than bit 2 which is more protected than bit 3 which is more protected than bit 4 (the least significant bit). These results illustrate the efficacy gains available through multiresolution modulation.

\section{CONCLUSIONS}

The advantages of employing an AMM scheme for multimedia traffic in MANET were inspected by means of analysis and simulation. Our results exemplified the significance of having a high-quality readily invertible approximation of the exact equation to facilitate automatically making decisions on switching thresholds for different modulation schemes based on the required QoS and channel conditions. This approach permits adaptation of both the shape and the size of the asymmetric signal constellation with the intention of improving the throughput for all the multimedia data while fulfilling the distinct QoS requirements for each traffic type under different channel conditions. The spectral efficiency gain achieved through the employment of multiresolution modulation at the physical layer is considerable, especially at low and moderate CNR. This performance gain is obtained by mapping higher priority buffer bits to higher protected bit positions within the symbol. In comparison to the previously proposed techniques, our approach is simpler and more robust.

\section{FUTURE WORKS}

Moving forward, we intend to extend this work to develop a cross-layer design based on QoS demands at the application layer in terms of latency and reliability, an ARQ at the data link layer to allow retransmissions (thus lowering the stringent demands at the PHY layer), and $\mathrm{AMM}$ at the physical layer to compensate for link quality fluctuations and to improve the spectral efficiency. Also, we will aim to extend this work by employing joint adaptive multiresolution modulation with retransmission diversity which captures the disparity in the QOS requirements for dissimilar traffic types. We also plan to evaluate the packet loss probability due to queuing (finite buffer length) by means of numerical analysis and comprehensive MATLAB simulations. Also, diversity combining techniques will be employed to merge multiple copies of received signals at the receiver into a single enhanced signal.

The prime objective of this research is to establish the "preeminent" approach that can concurrently support transmission of guaranteed real-time services and best-effort services over deprived wireless links. The throughput and delay performance of the ARQ protocol will be additionally enhanced by exploiting packet combining schemas at the data link layer. In particular, we will investigate the benefits with simple pre-detection / post-detection combining techniques, such as majority logic decoding and average diversity combiner. Though suboptimal, such approaches can extensively compress the buffer requirements and implementation complexity.

\section{ACKNOWLEDGEMENTS}

This research work is supported in part by the U.S. Army Research Laboratory under Cooperative Agreement W911NF-04-2-0054 and the National Science Foundation NSF/HRD 0931679. The views and conclusions contained in this document are those of the authors and should not be interpreted as representing the official policies, either expressed or implied, of the Army Research Laboratory or the National Science Foundation or the U. S. Government.

\section{REFERENCES}

[1] ITU-T Recommendation H.264 Advanced Video Coding for Generic Audiovisual Services, May 2003. 
International Journal of Wireless \& Mobile Networks (IJWMN) Vol. 4, No. 2, April 2012

[2] A. J. Goldsmith and P. Varaiya, "Capacity of fading channels with channel side information," IEEE Trans. Inform. Theory, vol. 43, pp. 1986-1992, Nov. 1997.

[3] A. J. Goldsmith and S.-G. Chua, "Variable-rate variable-power MQAM for fading channels,” IEEE Trans. Commun., vol. 45, pp. 1218-1230, Oct. 1997.

[4] M.S. Alouni, X. Tang, and A.J. Goldsmith, "An adaptive modulation scheme for simultaneous voice and data transmission over fading channels," IEEE J. Sel. Areas Commun., vol. 17, no. 5, pp.837-850, May 1999.

[5] C.S. Hwang and Y. Kim, "An adaptive modulation for integrated voice/data traffic over Nakagami fading channels," IEEE VTC Fall, Atlantic City, NJ, Sep. 2001, pp. 1649-1652.

[6] M. Pursley and J. Shea, "Nonuniform Phase-Shift-Key Modulation for Multimedia Multicast Transmission in Mobile Wireless Networks," IEEE Journal on Selected Areas in Communications, vol. 17, pp. 774-783, May 1999.

[7] M. Hossain, P. Vitthaladevuni, M. Alouni, V. Bhargava and, A. Goldsmith, "Adaptive hierarchical Modulation for Simultaneous Voice and Multiclass Data Transmission over Fading Channels," IEEE Transactions on Vehicular Technology, vol. 55, March 2006.

[8] T. Cover, "Broadcast Channels," IEEE Transactions on Information Theory, vol. IT-18, January 1972, pp. 2-14.

[9] C. W. Sundberg, W. C. Wong, and R. Steele, "Logarithmic PCM Weighted QAM Transmission over Gaussian and Rayleigh Fading Channels," IEE Proceedings, Pt. F, vol. 134, pp. 557-570, October 1987.

[10] R. Cox, J. Hagenauer, N. Seshadri and C. W. Sundberg, "Sub-band Speech Coding and Matched Convolution Channel Coding for Mobile Radio Channels," IEEE Transactions on Signal Processing, vol. 39, Aug. 1991, pp. 1717-1731.

[11] Jing Lu, A. Annamalai and D. R. Vaman, "Asymmetric PSK Constellation Design to Minimize Distortion in PCM Data Transmission,” Proc. IEEE Sarnoff Symposium, April 2008.

[12] K. Ramachandran, A. Ortega, K. Uz and M. Vetterli, "Multiresolution Broadcast for Digital HDTV using Joint Source/Channel Coding," IEEE Journal on Selected Areas in Communications, vol. 11, Jan. 1993, pp. 6-23.

[13] ETSI EN-300-744, Digital Video Broadcasting: Framing Structure, Channel Coding, and Channel Coding for Digital Terrestrial Television, 2001.

[14] A. Calderbank and N. Seshadri, "Multilevel Codes for Unequal Error Protection," IEEE Transactions on Information Theory, vol. 39, July 1993, pp. 1234-1248.

[15] Jing Lu, A. Annamalai, D. R. Vaman, "Reducing Signal Distortion Due to Transmission Errors via Multiresolution Digital Modulations," Proc. 2008 Wireless Telecommunications Symposium, California, April 2008.

[16] M. Sajadieh, F. Kschischang, and A. Leon-Garcia, "Modulation Assisted Unequal Error Protection over Fading Channel," IEEE Trans. on Vehicular Technology, vol. 47, Aug. 1998, pp. 900-908.

[17] M. Pursley and J. Shea, "Multimedia Multicast Wireless Communications with Phase-Shift-Key Modulation and Convolutional Coding," IEEE Journal on Selected Areas in Communications, vol. 17, Nov. 1999, pp. 1999-2010.

[18] M. Pursley and J. Shea, "Adaptive Nonuniform Phase Shift Key Modulation for Multimedia Traffic in Wireless Networks," IEEE Journal on Selected Areas in Communications, vol. 18, August 2000, pp. 1394-1407.

[19] P. Vitthaladevuni and M. Alouini, "Exact BER Computation of Generalized Hierarchical PSK Constellations," IEEE Transactions on Communications, vol. 51, December 2003, pp. 20302037. 
International Journal of Wireless \& Mobile Networks (IJWMN) Vol. 4, No. 2, April 2012

[20] P. Vittahaladevuni and M. S. Alouini, "A recursive algorithm for the exact BER computation of generalized hierarchical QAM constellations," IEEE Trans. Info. Theory, Jan. 2003, pp. 297307.

[21] J. Lassing, E. Strom, E. Agrell and T. Ottosson, "Computation of Exact Bit Error Rate of Coherent M-ary PSK with Gray Code Bit Mapping," IEEE Transactions on Communications, 2003.

[22] J. Liu and A. Annamalai, "Multiresolution Signaling for Multimedia Multicasting," Proc. 2004 IEEE Vehicular Technology Conference, Fall 2004, pp. 1088-1092.

[23] A. Annamalai and J. Liu, "A Cross-Layer Design Perspective for Multiresolution Signaling," Proc. 2004 IEEE GLOBECOM, November 2004, pp. 3342-3346.

[24] A. Annamalai, Jing Lu, D. Vaman, "A Receiver-Oriented Rate-Adaptation Strategy for Improving Network Efficiency in Mobile Ad-Hoc Networks," Proc. 2008 IEEE Sarnoff Symposium, Princeton, April 2008.

[25] A. Annamalai, Jing Lu, D. Vaman, "Improving the Efficiency of Wireless Networks via a Passive Rate-Adaptation Strategy," Proc. Wireless Telecommunications Symposium, California, April 2008.

\section{APPENDIX}

A summary of coefficients for average and individual bit PER probability using exponential approximation for 4-PSK, 8-PSK, 16-PSK, 64-QAM, and 256-QAM are listed in the following tables.

Table A-1. POLYNOMIAL COEFFICIENTS FOR 4-PSK (INDIVIDUAL BIT CLASS) PROBABILITY

\begin{tabular}{|c|c|c|c|c|c|c|}
\hline & & $\mathbf{P}_{\mathbf{4}}$ & $\mathbf{P}_{\mathbf{3}}$ & $\mathbf{P}_{\mathbf{2}}$ & $\mathbf{P}_{\mathbf{1}}$ & $\mathbf{P}_{\mathbf{0}}$ \\
\hline \multirow{4}{*}{$\mathbf{1}$} & $\mathbf{a}_{\boldsymbol{\beta}}{ }^{(\mathbf{1})}$ & $\mathrm{N} / \mathrm{a}$ & -52.3318 & 44.2865 & -11.2667 & 131.2686 \\
\cline { 2 - 7 } & $\mathbf{b}_{\boldsymbol{\beta}}{ }^{(\mathbf{1})}$ & $\mathrm{N} / \mathrm{a}$ & 2.1061 & -3.3530 & 0.1288 & 1.0276 \\
\cline { 2 - 7 } & $\mathbf{c}_{\boldsymbol{\beta}}{ }^{(\mathbf{1})}$ & $\mathrm{N} / \mathrm{a}$ & $1.1291 \mathrm{e}+04$ & $-9.7238 \mathrm{e}+03$ & $2.5352 \mathrm{e}+03$ & $-4.871 \mathrm{e}+03$ \\
\cline { 2 - 7 } & $\mathbf{d}_{\boldsymbol{\beta}}{ }^{(\mathbf{1})}$ & -93.3600 & 114.7000 & -35.7200 & 7.6130 & 5.5500 \\
\hline \multirow{4}{*}{$\mathbf{2}$} & $\mathbf{a}_{\boldsymbol{\beta}}{ }^{(\mathbf{2})}$ & $\mathrm{N} / \mathrm{a}$ & $1.0698 \mathrm{e}+03$ & $-1.3137 \mathrm{e}+03$ & 529.1871 & 60.9991 \\
\cline { 2 - 7 } & $\mathbf{b}_{\boldsymbol{\beta}}{ }^{(2)}$ & $\mathrm{N} / \mathrm{a}$ & -2.1140 & 3.3542 & -0.1252 & 0.0061 \\
\cline { 2 - 7 } & $\mathbf{c}_{\boldsymbol{\beta}}{ }^{(\mathbf{2})}$ & $\mathrm{N} / \mathrm{a}$ & $-1.2594 \mathrm{e}+05$ & $1.5337 \mathrm{e}+05$ & $-6.1626 \mathrm{e}+04$ & $3.4314 \mathrm{e}+03$ \\
\cline { 2 - 7 } & $\mathbf{d}_{\boldsymbol{\beta}}{ }^{(2)}$ & 415.4000 & -643.7000 & 405.6000 & -140.8000 & 32.5700 \\
\hline
\end{tabular}

Table A-2. POLYNOMIAL COEFFICIENTS FOR 4-PSK (AVERAGE BIT CLASS) PROBABILITY

\begin{tabular}{|c|c|c|c|c|c|}
\hline & $\mathbf{P}_{\mathbf{4}}$ & $\mathbf{P}_{\mathbf{3}}$ & $\mathbf{P}_{\mathbf{2}}$ & $\mathbf{P}_{\mathbf{1}}$ & $\mathbf{P}_{\mathbf{0}}$ \\
\hline $\mathbf{a}_{\boldsymbol{\beta}}$ & $\mathrm{N} / \mathrm{a}$ & 0 & 0 & 0 & 127.4544 \\
\hline $\mathbf{b}_{\boldsymbol{\beta}}$ & N/a & 0 & 0 & 0 & 0.5161 \\
\hline $\mathbf{c}_{\boldsymbol{\beta}}$ & N/a & 0 & 0 & 0 & $-4.4866 \mathrm{e}+03$ \\
\hline $\mathbf{d}_{\boldsymbol{\beta}}$ & 639.0000 & -868.8000 & 487.7000 & -153.5000 & 32.5100 \\
\hline
\end{tabular}

Table A-3. POLYNOMIAL COEFFICIENTS FOR 8-PSK (INDIVIDUAL BIT CLASS) PROBABILITY

\begin{tabular}{|c|c|c|c|c|c|c|}
\hline & & $\mathbf{P}_{\mathbf{4}}$ & $\mathbf{P}_{\mathbf{3}}$ & $\mathbf{P}_{\mathbf{2}}$ & $\mathbf{P}_{\mathbf{1}}$ & $\mathbf{P}_{\mathbf{0}}$ \\
\hline \multirow{4}{*}{$\mathbf{1}$} & $\mathbf{a}_{\boldsymbol{\beta}}{ }^{\left({ }^{1}\right)}$ & $\mathrm{N} / \mathrm{a}$ & $3.3107 \mathrm{e}+03$ & $-2.6421 \mathrm{e}+03$ & 416.5972 & 104.9653 \\
\cline { 2 - 7 } & $\mathbf{b}_{\boldsymbol{\beta}}{ }^{(\mathbf{1})}$ & $\mathrm{N} / \mathrm{a}$ & 11.3557 & -13.4411 & 2.4242 & 0.8750 \\
\cline { 2 - 7 } & $\mathbf{c}_{\boldsymbol{\beta}}{ }^{\left({ }^{1}\right)}$ & $\mathrm{N} / \mathrm{a}$ & $-1.0933 \mathrm{e}+05$ & $7.9648 \mathrm{e}+04$ & $-7.3081 \mathrm{e}+03$ & $-3.6766 \mathrm{e}+03$ \\
\cline { 2 - 7 } & $\mathbf{d}_{\boldsymbol{\beta}}{ }^{(\mathbf{1})}$ & 270.8000 & -155.6000 & 46.3600 & -3.3020 & 6.0670 \\
\hline
\end{tabular}


International Journal of Wireless \& Mobile Networks (IJWMN) Vol. 4, No. 2, April 2012

\begin{tabular}{|c|c|c|c|c|c|c|}
\hline \multirow{4}{*}{2} & $\mathbf{a}_{\beta}{ }^{(2)}$ & N/a & -495.0799 & 515.9588 & -176.1712 & 81.9131 \\
\hline & $b_{\beta}^{(2)}$ & $\mathrm{N} / \mathrm{a}$ & -1.7758 & 1.0259 & 0.2603 & -0.0148 \\
\hline & $\mathbf{c}_{\beta}^{(2)}$ & $\mathrm{N} / \mathrm{a}$ & $1.7697 \mathrm{e}+04$ & $-1.8307 e+04$ & $6.2392 \mathrm{e}+03$ & $-1.6219 \mathrm{e}+03$ \\
\hline & $d_{\beta}^{(2)}$ & -900.5000 & 1013.0000 & -303.8000 & -16.7000 & 27.0100 \\
\hline \multirow{4}{*}{3} & $\mathbf{a}_{\boldsymbol{\beta}}^{\left({ }^{(3)}\right.}$ & N/a & $1.3104 \mathrm{e}+03$ & $-2.2445 e+03$ & $1.1351 \mathrm{e}+03$ & -99.8683 \\
\hline & $\mathbf{b}_{\beta}^{(3)}$ & N/a & 2.2520 & -0.7339 & 0.0943 & -0.0042 \\
\hline & $\mathbf{c}_{\beta}^{(3)}$ & N/a & $-1.3551 e+04$ & $2.8639 e+04$ & $-1.6005 e+04$ & $1.4410 \mathrm{e}+03$ \\
\hline & $\mathbf{d}_{\beta}^{(3)}$ & 563.8000 & -947.4000 & 648.7000 & -251.3000 & 61.0100 \\
\hline
\end{tabular}

Table A-4. POLYNOMIAL COEFFICIENTS FOR 8-PSK (AVERAGE BIT CLASS) PROBABILITY

\begin{tabular}{|c|c|c|c|c|c|}
\hline & $\mathbf{P}_{\mathbf{4}}$ & $\mathbf{P}_{\mathbf{3}}$ & $\mathbf{P}_{\mathbf{2}}$ & $\mathbf{P}_{\mathbf{1}}$ & $\mathbf{P}_{\mathbf{0}}$ \\
\hline $\mathbf{a}_{\boldsymbol{\beta}}$ & $\mathrm{N} / \mathrm{a}$ & 0 & 0 & 0 & 93.6387 \\
\hline $\mathbf{b}_{\boldsymbol{\beta}}$ & N/a & 0 & 0 & 0 & 0.1529 \\
\hline $\mathbf{c}_{\beta}$ & N/a & 0 & 0 & 0 & $-2.4908 \mathrm{e}+03$ \\
\hline $\mathbf{d}_{\beta}$ & $6.3440 \mathrm{e}-11$ & 166.7000 & -50.0000 & -76.67 & 44.75 \\
\hline
\end{tabular}

Table A-5. POLYNOMIAL COEFFICIENTS FOR 64-QAM (INDIVIDUAL BIT CLASS) PROBABILITY

\begin{tabular}{|c|c|c|c|c|c|c|}
\hline & & $\mathbf{P}_{4}$ & $\mathbf{P}_{3}$ & $\mathbf{P}_{2}$ & $\mathbf{P}_{1}$ & $\mathbf{P}_{0}$ \\
\hline & $\mathbf{a}_{\beta}{ }^{(1)}$ & N/a & -910.0549 & $1.1941 \mathrm{e}+03$ & -514.9076 & 107.6440 \\
\hline & $\mathbf{b}_{\beta}{ }^{(1)}$ & N/a & 2.0915 & -0.8068 & -1.1349 & 0.5335 \\
\hline & $\mathbf{c}_{\beta}{ }^{(1)}$ & N/a & $3.6149 \mathrm{e}+04$ & $-4.2578 \mathrm{e}+04$ & $1.6469 \mathrm{e}+04$ & $-2.4243 e+03$ \\
\hline & $\mathbf{d}_{\beta}{ }^{(1)}$ & 215.9000 & -124.9000 & 54.8100 & 0.05396 & 8.8710 \\
\hline & $\mathbf{a}_{\beta}{ }^{(2)}$ & N/a & -938.0158 & 845.9982 & -221.7132 & 78.8082 \\
\hline & $\mathbf{b}_{\beta}^{(2)}$ & N/a & -0.3735 & 0.1735 & 0.0628 & -0.0038 \\
\hline & $\mathbf{c}_{\beta}{ }^{(2)}$ & $\mathrm{N} / \mathrm{a}$ & $5.2979 \mathrm{e}+04$ & $-4.6210 e+04$ & $1.1348 \mathrm{e}+04$ & $-1.6320 e+03$ \\
\hline & $d_{\beta}^{(2)}$ & 559.2000 & -818.3000 & 491.3000 & -147.7000 & 39.8500 \\
\hline & $\mathbf{a}_{\beta}{ }^{(3)}$ & N/a & $5.5567 \mathrm{e}+03$ & $-5.5940 \mathrm{e}+03$ & $1.7888 \mathrm{e}+03$ & -63.3358 \\
\hline & $\mathbf{b}_{\beta}^{(3)}$ & N/a & 0.3320 & -0.0860 & 0.0100 & $-4.3182 \mathrm{e}-04$ \\
\hline & $\mathbf{c}_{\beta}{ }^{(3)}$ & $\mathrm{N} / \mathrm{a}$ & $-4.2313 e+05$ & $4.1430 \mathrm{e}+05$ & $-1.2817 e+05$ & $9.4184 \mathrm{e}+03$ \\
\hline & $\mathbf{d}_{\beta}{ }^{(3)}$ & 785.4000 & -1265.0000 & 816.1000 & -286.7000 & 70.6500 \\
\hline
\end{tabular}

Table A-6. POLYNOMIAL COEFFICIENTS FOR 64-QAM (AVERAGE BIT CLASS) PROBABILITY

\begin{tabular}{|c|c|c|c|c|c|}
\hline & $\mathbf{P}_{\mathbf{4}}$ & $\mathbf{P}_{\mathbf{3}}$ & $\mathbf{P}_{\mathbf{2}}$ & $\mathbf{P}_{\mathbf{1}}$ & $\mathbf{P}_{\mathbf{0}}$ \\
\hline $\mathbf{a}_{\beta}$ & N/a & 0 & 0 & 0 & 80.1406 \\
\hline $\mathbf{b}_{\boldsymbol{\beta}}$ & N/a & 0 & 0 & 0 & 0.0247 \\
\hline $\mathbf{c}_{\beta}$ & N/a & 0 & 0 & 0 & $-1.8278 \mathrm{e}+03$ \\
\hline $\mathbf{d}_{\beta}$ & 1181.0000 & -1671.0000 & 958.9000 & -306.3000 & 70.2100 \\
\hline
\end{tabular}

Table A-7. POLYNOMIAL COEFFICIENTS FOR 16-PSK (INDIVIDUAL BIT CLASS) PROBABILITY

\begin{tabular}{|c|c|c|c|c|c|c|}
\hline \multirow{5}{*}{1} & & $\mathrm{P}_{4}$ & $\mathrm{P}_{3}$ & $\mathrm{P}_{2}$ & $\mathrm{P}_{1}$ & $\mathrm{P}_{0}$ \\
\hline & $\mathbf{a}_{\beta}{ }^{(1)}$ & N/a & $3.0777 \mathrm{e}+03$ & $-3.1923 e+03$ & 886.7117 & -4.9225 \\
\hline & $\mathbf{b}_{\beta}{ }^{\left({ }^{\prime}\right)}$ & N/a & 16.8240 & -19.0129 & 3.8032 & 0.7708 \\
\hline & $\mathbf{c}_{\beta}{ }^{(1)}$ & $\mathrm{N} / \mathrm{a}$ & $-7.9575 e+04$ & $7.7277 e+04$ & $-1.9794 \mathrm{e}+04$ & 383.0110 \\
\hline & $d_{\beta}{ }^{(1)}$ & 1765.0000 & -1630.0000 & 565.8000 & -79.8000 & 9.9600 \\
\hline
\end{tabular}


International Journal of Wireless \& Mobile Networks (IJWMN) Vol. 4, No. 2, April 2012

\begin{tabular}{|c|c|c|c|c|c|c|}
\hline \multirow{4}{*}{2} & $\mathbf{a}_{\beta}{ }^{(2)}$ & $\mathrm{N} / \mathrm{a}$ & -450.6153 & 776.0497 & -415.7862 & 103.6366 \\
\hline & $\mathbf{b}_{\beta}{ }^{(2)}$ & $\mathrm{N} / \mathrm{a}$ & -1.4104 & -0.1113 & 0.5506 & -0.0343 \\
\hline & $\mathbf{c}_{\beta}{ }^{(2)}$ & $\mathrm{N} / \mathrm{a}$ & $2.4628 \mathrm{e}+04$ & $-3.1731 e+04$ & $1.3658 \mathrm{e}+04$ & $-2.2255 e+03$ \\
\hline & $d_{\beta}{ }^{(2)}$ & 826.4000 & -1027.0000 & 570.1000 & -162.7000 & 33.9600 \\
\hline \multirow{4}{*}{3} & $\mathbf{a}_{\beta}^{(3)}$ & $\mathrm{N} / \mathrm{a}$ & 169.9268 & -210.3289 & 108.2366 & 30.9133 \\
\hline & $\mathbf{b}_{\beta}^{(3)}$ & N/a & -0.1718 & 0.3988 & -0.0907 & 0.0059 \\
\hline & $\mathbf{c}_{\beta}^{(3)}$ & N/a & $-5.7246 e+04$ & $7.7019 \mathrm{e}+03$ & $-3.9217 e+03$ & 58.3874 \\
\hline & $d_{\beta}{ }^{(3)}$ & 879.5000 & -1376.0000 & 867.4000 & -287.9000 & 63.6500 \\
\hline \multirow{4}{*}{4} & $\mathbf{a}_{\beta}{ }^{(4)}$ & $\mathrm{N} / \mathrm{a}$ & 125.8574 & $-1.3741 e+03$ & 988.4554 & -90.4477 \\
\hline & $\mathbf{b}_{\beta}^{(4)}$ & $\mathrm{N} / \mathrm{a}$ & 1.4002 & -0.8544 & 0.1702 & -0.0106 \\
\hline & $\mathbf{c}_{\beta}{ }^{(4)}$ & N/a & $2.1002 \mathrm{e}+05$ & $-1.5881 e+05$ & $2.8226 e+04$ & $-1.5010 \mathrm{e}+03$ \\
\hline & $d_{\beta}{ }^{(4)}$ & 1426.0000 & -2171.0000 & 1317.0000 & -443.2000 & 95.0200 \\
\hline
\end{tabular}

Table A-8. POLYNOMIAL COEFFICIENTS FOR 16-PSK (AVERAGE BIT CLASS) PROBABILITY

\begin{tabular}{|c|c|c|c|c|c|}
\hline & $\mathbf{P}_{\mathbf{4}}$ & $\mathbf{P}_{\mathbf{3}}$ & $\mathbf{P}_{\mathbf{2}}$ & $\mathbf{P}_{\mathbf{1}}$ & $\mathbf{P}_{\mathbf{0}}$ \\
\hline $\mathbf{a}_{\boldsymbol{\beta}}$ & $\mathrm{N} / \mathrm{a}$ & 0 & 0 & 0 & 44.7276 \\
\hline $\mathbf{b}_{\boldsymbol{\beta}}$ & $\mathrm{N} / \mathrm{a}$ & 0 & 0 & 0 & 0.0379 \\
\hline $\mathbf{c}_{\boldsymbol{\beta}}$ & $\mathrm{N} / \mathrm{a}$ & 0 & 0 & 0 & 5.7858 \\
\hline $\mathbf{d}_{\boldsymbol{\beta}}$ & 1892.0000 & -2684.0000 & 1521.0000 & -477.8000 & 95.4300 \\
\hline
\end{tabular}

Table A-9. POLYNOMIAL COEFFICIENTS FOR 256-QAM (INDIVIDUAL BIT CLASS) PROBABILITY

\begin{tabular}{|c|c|c|c|c|c|c|}
\hline & & $\mathrm{P}_{4}$ & $\mathrm{P}_{3}$ & $\mathrm{P}_{2}$ & $\mathrm{P}_{1}$ & $\mathrm{P}_{0}$ \\
\hline \multirow{4}{*}{$\mathbf{1}$} & $\mathbf{a}_{\beta}{ }^{(1)}$ & $\mathrm{N} / \mathrm{a}$ & 214.1059 & 199.7885 & -303.1980 & 94.6347 \\
\hline & $\mathbf{b}_{\beta}{ }^{(1)}$ & $\mathrm{N} / \mathrm{a}$ & 4.1234 & -2.5915 & -0.7370 & 0.5077 \\
\hline & $\mathbf{c}_{\beta}{ }^{(1)}$ & $\mathrm{N} / \mathrm{a}$ & $2.1984 \mathrm{e}+04$ & $-3.0988 e+04$ & $1.4448 \mathrm{e}+04$ & $-2.3255 e+03$ \\
\hline & $d_{\beta}{ }^{(1)}$ & 1664.0000 & -1553.0000 & 558.3000 & -73.9800 & 12.6500 \\
\hline \multirow{4}{*}{2} & $\mathbf{a}_{\beta}{ }^{(2)}$ & $\mathrm{N} / \mathrm{a}$ & 77.8998 & 224.0731 & -233.3701 & 83.0034 \\
\hline & $\mathbf{b}_{\beta}{ }^{(2)}$ & $\mathrm{N} / \mathrm{a}$ & -0.1363 & -0.1557 & 0.1407 & -0.0089 \\
\hline & $\mathbf{c}_{\beta}{ }^{(2)}$ & $\mathrm{N} / \mathrm{a}$ & $-2.3975 e+04$ & $1.7334 \mathrm{e}+04$ & $-2.0925 \mathrm{e}+03$ & -703.7629 \\
\hline & $d_{\beta}^{(2)}$ & 619.0000 & -753.4000 & 450.0000 & -139.6000 & 39.3500 \\
\hline \multirow{4}{*}{3} & $\mathbf{a}_{\beta}^{(3)}$ & $\mathrm{N} / \mathrm{a}$ & 939.0930 & $-1.3508 \mathrm{e}+03$ & 572.5007 & -8.7737 \\
\hline & $\mathbf{b}_{\beta}^{(3)}$ & $\mathrm{N} / \mathrm{a}$ & -0.0857 & 0.1073 & -0.0229 & 0.0014 \\
\hline & $\mathbf{c}_{\beta}{ }^{(3)}$ & $\mathrm{N} / \mathrm{a}$ & $2.5014 \mathrm{e}+04$ & 72.5132 & $-8.7253 e+03$ & 766.6995 \\
\hline & $\mathbf{d}_{\beta}^{(3)}$ & 955.7000 & -1446.0000 & 890.6000 & -288.9000 & 70.4800 \\
\hline \multirow{4}{*}{4} & $\mathbf{a}_{\beta}{ }^{(4)}$ & $\mathrm{N} / \mathrm{a}$ & $-1.8191 e+03$ & 385.9918 & 663.9760 & -85.3526 \\
\hline & $\mathbf{b}_{\beta}^{(4)}$ & $\mathrm{N} / \mathrm{a}$ & 0.2151 & -0.1277 & 0.0251 & -0.0016 \\
\hline & $\mathbf{c}_{\beta}{ }^{(4)}$ & $\mathrm{N} / \mathrm{a}$ & $2.0229 \mathrm{e}+05$ & $-1.8229 e+05$ & $3.6211 \mathrm{e}+04$ & $-1.8963 e+03$ \\
\hline & $d_{\beta}^{(4)}$ & 1494.0000 & -2260.0000 & 1362.0000 & -450.6000 & 102.4000 \\
\hline
\end{tabular}

Table A-10. P OLYNOMIAL COEFFICIENTS FOR 256-QAM (AVERAGE BIT CLASS) PROBABILITY

\begin{tabular}{|c|c|c|c|c|c|}
\hline & $\mathbf{P}_{\mathbf{4}}$ & $\mathbf{P}_{\mathbf{3}}$ & $\mathbf{P}_{\mathbf{2}}$ & $\mathbf{P}_{\mathbf{1}}$ & $\mathbf{P}_{\mathbf{0}}$ \\
\hline $\mathbf{a}_{\boldsymbol{\beta}}$ & $\mathrm{N} / \mathrm{a}$ & 0 & 0 & 0 & 63.2383 \\
\hline $\mathbf{b}_{\boldsymbol{\beta}}$ & $\mathrm{N} / \mathrm{a}$ & 0 & 0 & 0 & 0.0061 \\
\hline $\mathbf{c}_{\boldsymbol{\beta}}$ & $\mathrm{N} / \mathrm{a}$ & 0 & 0 & 0 & $-1.1143 \mathrm{e}+03$ \\
\hline $\mathbf{d}_{\boldsymbol{\beta}}$ & 1735.0000 & -2475.0000 & 1426.0000 & -458.30000 & 101.0000 \\
\hline
\end{tabular}


International Journal of Wireless \& Mobile Networks (IJWMN) Vol. 4, No. 2, April 2012 Authors

For undergraduate studies, Justin James attended Tuskegee University where he majored in Electrical Engineering. While obtaining his Bachelors' Degree (2006), Justin was recognized by several honor societies including Golden Key International Honor Society (Tuskegee University Honor Society), Eta Kappa $\mathrm{Nu}$ (Electrical Engineering Honor Society), and Beta Kappa Chi (Scientific Honor Society). For his Masters' studies (2008), Justin also attended Tuskegee University where he focused on Microelectronics. Justin is presently enrolled in the Department of Electrical and Computer Engineering at Prairie View A\&M University where he is conducting research related to tactical and emergency

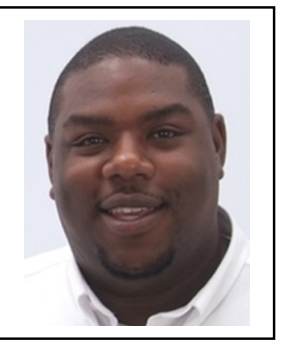
wireless networks. Justin is under the co-advisement of Dr. D. R. Vaman and Dr. A. A. Annamalai. Currently in his fourth year of doctoral studies, he has finished all required coursework and is vigorously working on his dissertation.

Dr. Annamalai is presently the Director of Center of Excellence for Communication Systems Technology Research, a Texas A\&M Board of Regents approved University Research Center at the Prairie View A\&M University, and a tenured faculty member in the Department of Electrical and Computer Engineering. He has over 16 years of research/teaching experience in wireless communications at Motorola, University of Victoria, Air Force Research Laboratory, Virginia Tech and PVAMU with approximately 200 peer-reviewed publications and 5 book chapters. Dr. Annamalai has been honored by his colleagues on numerous occasions for his excellence in research including winning

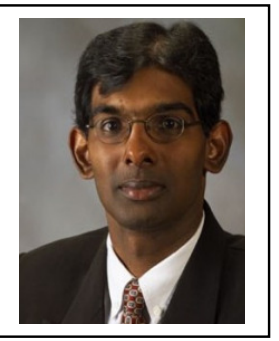
the 2011 Roy G. Perry College of Engineering Outstanding Faculty (Research) Award, IEEE Leon Kirchmayer Prize Paper award, ASEE/AFOSR Summer Faculty Fellowships, NSERC Doctoral Prize, CAGS/UMI Distinguished Doctoral Dissertation Award, IEEE VTS/Motorola Daniel E. Noble Fellowship, among others. He had served on the Editorial Boards of four IEEE journals/transactions in the last 12 years, and has helped to organize a few major IEEE conferences on wireless communications including serving in the capacity of Technical Program Chair of the 2002 IEEE Vehicular Technology Conference in Vancouver, Canada. His current research interests include cooperative spectrum sensing, compressive sensing, cross-layer design for scalable multimedia transmission and cooperative wireless communications.

Dr. O. Odejide is a Post-Doctoral Researcher in the Department of Electrical and Computer Engineering at Prairie View A\&M University. Dr.Odejide professional preparation includes: Ph.D., Electrical Engineering, Aug. 2009, Prairie View A\&M University, Prairie View, TX; M.S Computer and Information Systems Engineering, Aug, 2004, Tennessee State University; Microsoft Certified System Engineer (Windows NT 4.0 \& 2000); and B.SC Electrical and Electronic Engineering, May, 1997, University of Ibadan, Nigeria. Dr. Odejide's research interests include compressive sensing, cooperative communications,

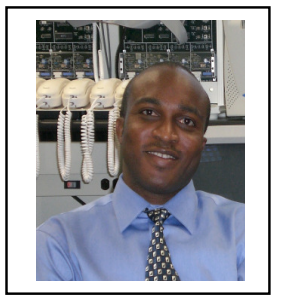
cognitive radios, waveform design for integrated voice/data networks, cross-layer optimization, wireless link adaptation and smart grid.

Dr. D. R. Vaman is Texas Instrument Endowed Chair Professor and Texas A\&M Board of Regents Professor in the Department of Electrical and Computer Engineering at Prairie View A\&M University where he is also the Director of the Center of Excellence in Battlefield Research (CEBCOM). Dr. Vaman's professional preparation includes: The City University of New York, New York Electrical Engg., Ph.D. 1979; The City College of New York, New York Electrical Engg., M.E. 1975; Regional Engineering College, Warangal, India Electronic Instrumentation, M.Tech. 1972; and Regional Engineering College, Warangal, India Electrical Engg., B.E. 1970. Professor Vaman has published over 200 journal and conference papers. Also, he has written over 26 patents including 14 issued. 